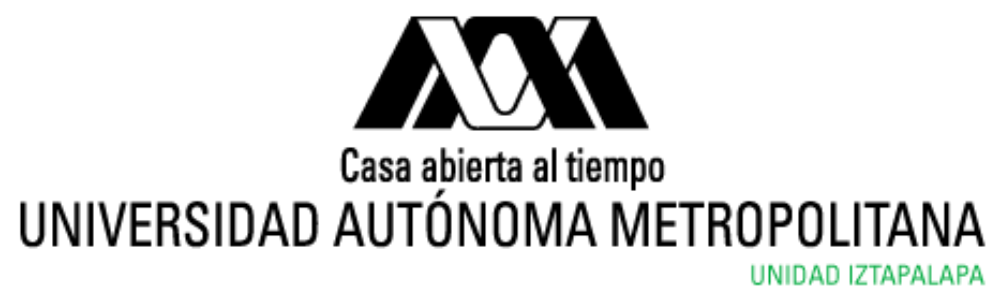

\title{
INHIBICIÓN DE LA AUTOFAGIA COMO MECANISMO DE INDUCCIÓN DE SENESCENCIA EN ASTROCITOS PRIMARIOS DE RATA.
}

\author{
TES IS \\ Que para obtener el grado de \\ Maestro en Biología Experimental \\ PRESENTA \\ Biól. Exp. Gibrán Pedraza Vázquez \\ Comité tutoral: \\ Co-directora interna: Dra. Mina Konigsberg Fainstein \\ Co-director externo: Dr. Armando Luna López \\ Asesora: Dra. Susana Castro Obregón
}

Ciudad de México, 15 de noviembre de 2016 
Este trabajo fue realizado en el Laboratorio de Bioenergética y Envejecimiento Celular del departamento de Ciencias de la Salud, en la División de Ciencias Biológicas y de la Salud de la Universidad Autónoma Metropolitana Unidad Iztapalapa.

El Programa de Maestría en Biología Experimental de la Universidad Autónoma Metropolitana pertenece al Programa Nacional de Posgrados de Calidad (PNPC) del CONACYT, registro 001481, en el Nivel Consolidado, y cuenta con apoyo del mismo Consejo, clave DAFCYT-2003IMPTNNN0020.

Número de registro de la beca otorgada por el CONACYT: 398193

Número de becario: $570358 \quad$ CVU: 634559 
El jurado designado por la Comisión Académica del Posgrado en Biologia Experimental de la División de Ciencias Biológicas y de la Salud de la Universidad Autónoma Metropolitana aprobó la Tesis titulada: “INHIBICIÓN DE LA AUTOFAGIA COMO MECANISMO DE INDUCCIÓN DE SENESCENCIA EN ASTROCITOS PRIMARIOS DE RATA.", que presentó

\author{
Biol. Exp. Gibrán Pedraza Vázquez \\ El dia 15 de noviembre del año 2016.
}

\title{
MIEMBROS DEL JURADO
}

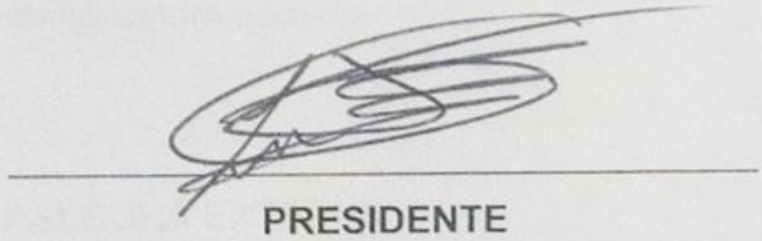

Dr. Luis Enrique Gómez Quiroz

Departamento de Ciencias de la Salud

Universidad Autónoma Metropolitana

moma Edops Du $\varphi$

VOCAL

Dra. Norma Edith López Díaz-Guerrero

Departamento de Ciencias de la Salud Universidad Autónoma Metropolitana

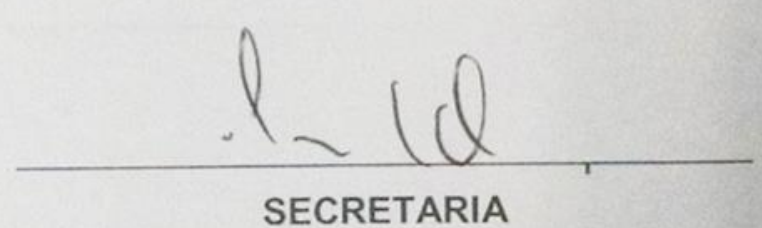

Dra. Susana Castro Obregón Instituto de Fisiología Celular Universidad Nacional Autónoma de México

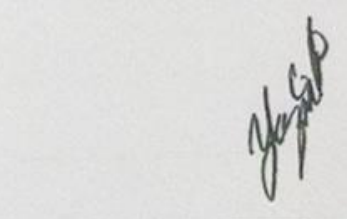

VOCAL

Dra. Viridiana Yazmín González Puertos

Departamento de Ciencias de la Salud Universidad Autónoma Metropolitana 


\section{CO-DIRECTORES}

Dr. Armando Luna López

Departamento de Investigación Básica

Instituto Nacional de Geriatría

allbioexp@yahoo.com

Dra. Mina Konigsberg Fainstein

Departamento de Ciencias de la Salud

Universidad Autónoma Metropolitana

mkf@xanum.uam.mx

ASESORA EXTERNA

Dra. Susana Castro Obregón

Departamento de Neurofisiología y Desarrollo

Instituto de Fisiología Celular, UNAM

scastro@ifc.unam.mx 


\section{AGRADECIMIENTOS}

A la Dra. Mina Konigsberg Fainstein por todo el apoyo que me ha brindado, los consejos y palabras de aliento, gracias por abrirme las puertas de su laboratorio.

Al Dr. Armando Luna López por su apoyo incondicional, los consejos, preguntas y cuestionamientos siempre oportunos, pero, sobre todo, gracias por la amistad que me ha sabido ofrecer durante todo este tiempo.

A la Dra. Susana Castro Obregón por su disponibilidad y amabilidad, además de sus valiosos comentarios y consejos que permitieron enriquecer este trabajo.

A los Doctores Luis Enrique Gómez Quiróz, Viridiana Yazmín Gonzáles Puertos y Norma Edith López Díaz-Guerrero por sus valiosas observaciones a esta tesis.

A la MVZ Rocío González Vieira del bioterio de la UAM-I por proveer los animales utilizados en este trabajo.

A mis compañeros del laboratorio. Rafa, Luis, Sandra Li, Paola, Ismerai, Viridiana, Pedro, Ulalume, Elisa, Verónica, Roberto, Alejandro, René por siempre hacerme sentir como en casa, sepan que en verdad ahora los considero parte de mi familia.

A mis amigos. Betty, Bea, Wendy, Arturo, Soraya, Sandra Li, Rafa, Paola, Pedro, Ismerai, Luis Maciel, Axel Urbina, Samara y Luis Eduardo por siempre estar cerca, ayudarme y sobre todo animarme cuando fue necesario. Sin ustedes el camino habría sido mucho más difícil, de verdad, gracias.

A Zaira, gracias. 


\section{DEDICATORIAS}

Para Ary. Gracias por llegar en el momento más inesperado, por todos tus ánimos, consejos, tiempo y cariño. Lo prometido es deuda: Mujer oculta, maestra del misterio, nombre incierto // en la distancia, anudando abrazos incontenibles... ¡Que perduren los misterios, los haikus y los diluvios universales!

Para mis padres, mi hermana y mi familia en general. Papá, gracias por enseñarme a ver la vida como biólogo desde que era un niño, por impulsarme a hacer lo que me gusta y pelear por mis ideales. Siempre, pero siempre serás mi biólogo favorito.

Mamá, gracias por enseñarme a ser independiente, valorar todo lo que hago y por apoyarme en todo lo que intento.

Eve, por recibirme con un abrazo en todo momento, por saber hacerme reír, por siempre estar disponible para mí, escucharme y animarme. Gracias hermanita.

Gracias por todo su apoyo y cariño, ustedes son quienes caminan conmigo en todo momento. ¡Los amo!

Para Santi, porque siempre ha sido todo para ti. Eres el motor que me da la fuerza necesaria para continuar, a pesar de todo y de todos. Gracias por enseñarme que se puede aprender a caminar dos veces, gracias por todos los abrazos que acompañados de un "Papá, te quiero mucho" me hacen sentir que la felicidad más pura emana siempre de tu sonrisa. Te amo hijo, y eso es para siempre. 
Índice

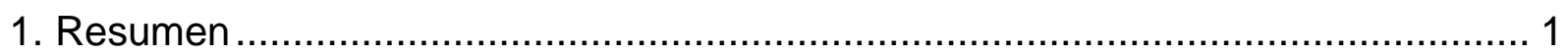

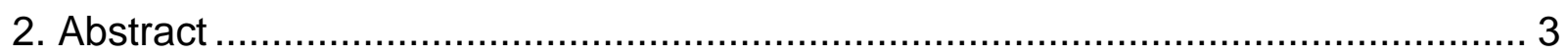

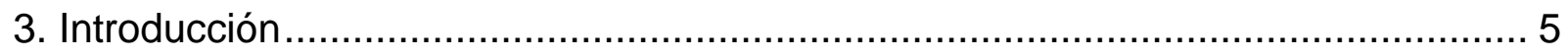

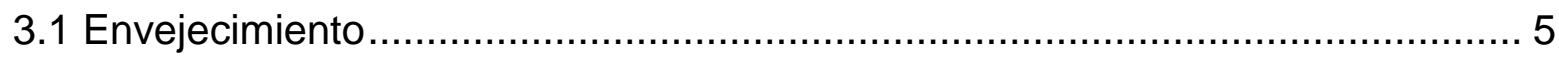

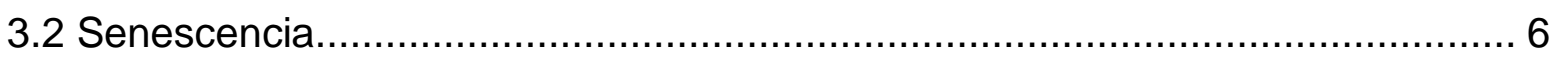

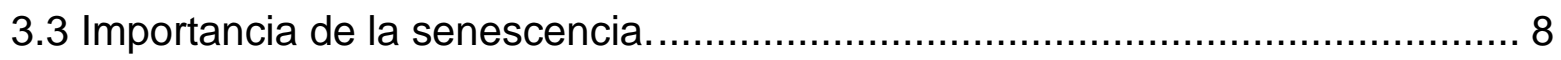

3.4 Astrocitos y homeostasis del tejido nervioso.................................................. 9

3.5 Autofagia y control de la proteostasis. .................................................... 10

3.6 Pérdida de la proteostasis y su relación con la senescencia. ......................... 13

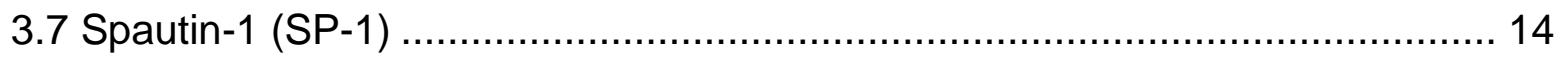

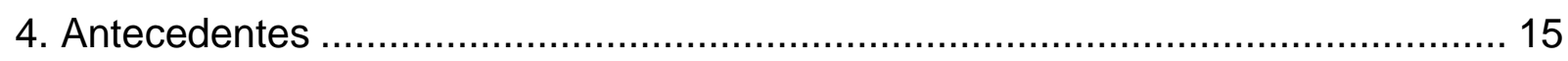

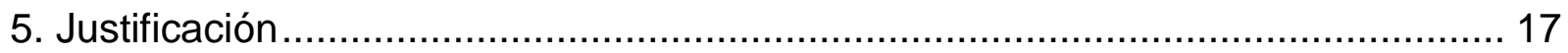

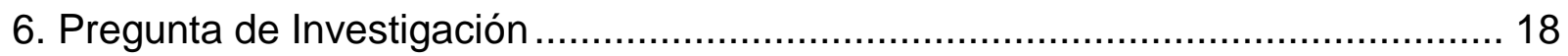

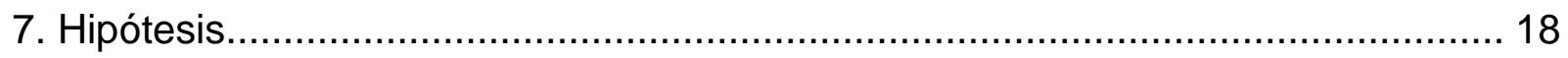

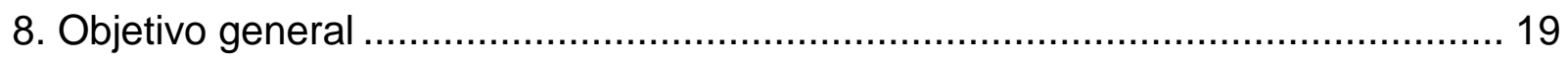

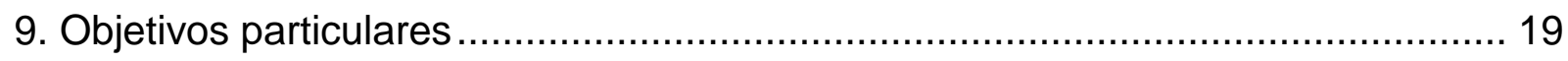

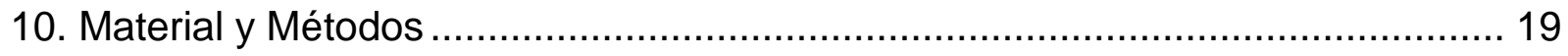

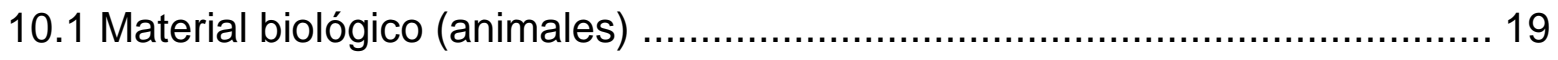


10.2 Obtención del cultivo primario de astrocitos de rata.

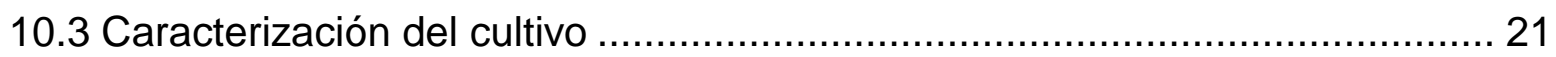

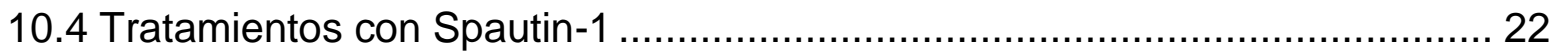

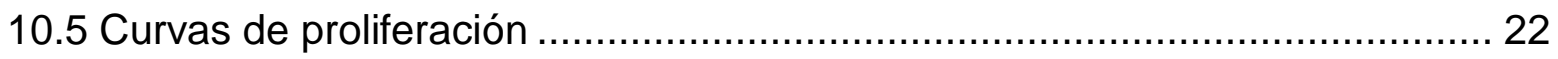

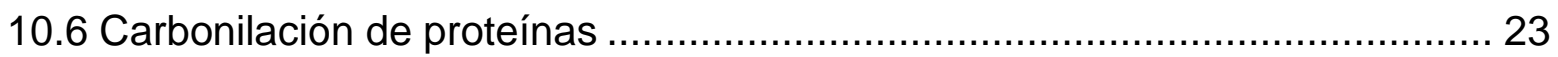

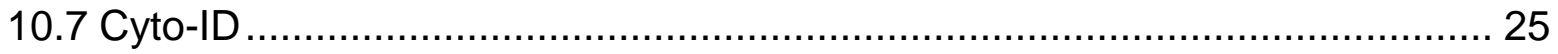

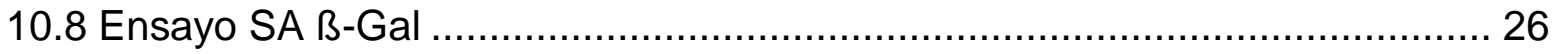

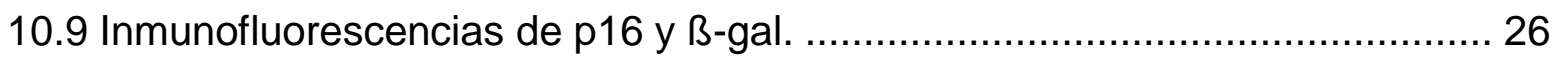

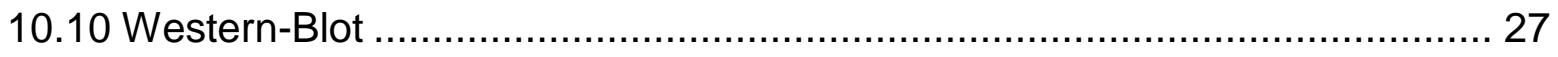

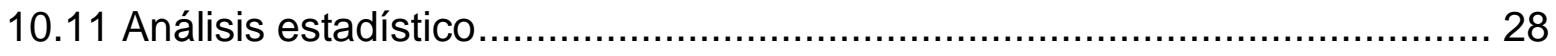

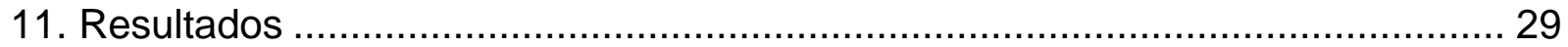

11.1 Caracterización del cultivo primario de astrocitos de rata............................22

11.2 Efecto de SP-1 sobre el cultivo primario de astrocitos de rata...................... 30

11.2.1 Curvas de proliferación del cultivo primario con SP-1 .............................. 31

11.2.2 Niveles de carbonilación de proteínas generados por SP-1 ….................. 34

11.2.3 Ensayo de detección de autofagia con Cyto-ID ...................................... 35

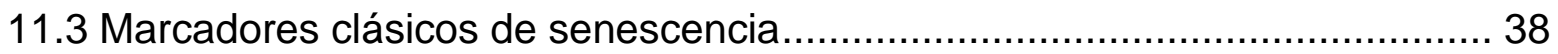

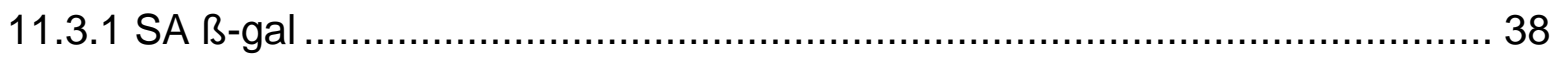

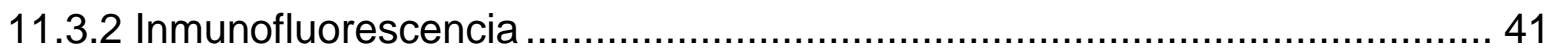


11.3.3 Western-Blot de los inhibidores del ciclo celular

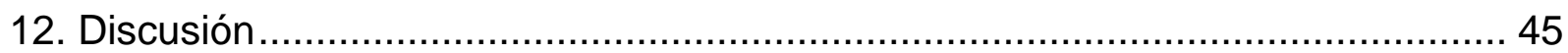

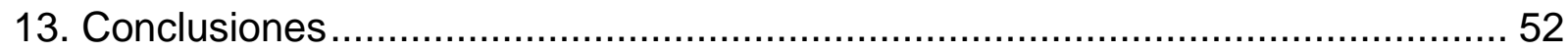

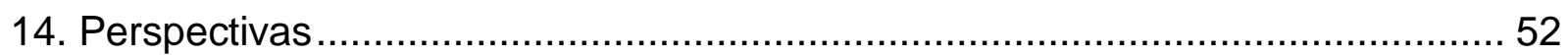

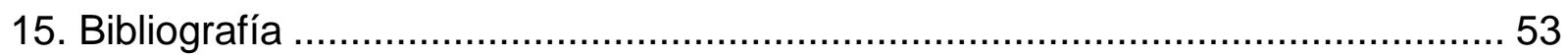




\section{Resumen}

La senescencia es un fenómeno que se caracteriza por la detención permanente de la proliferación en respuesta a un daño o estrés, y por eso principalmente ha sido relacionado principalmente con el envejecimiento y enfermedades asociadas a este. Sin embargo, recientemente se ha demostrado su participación en otros procesos fisiológicos e incluso durante el desarrollo embrionario, donde la inducción de senescencia no se da en respuesta a un estrés.

La participación de las células senescentes en las enfermedades neurodegenerativas asociadas a la edad, es un tema que ha generado un creciente interés en los últimos años, por el aumento en la cantidad de personas que las padecen.

Los astrocitos son las células del cerebro más numerosas y han recibido particular énfasis, ya que son las encargadas de la homeostasis del cerebro, por lo que la pérdida de sus funciones al adquirir el fenotipo senescente representa un problema en el microambiente del tejido, lo que pudiera derivar en neurodegeneración.

La pérdida de la proteostasis en el sistema nervioso central ha sido asociada con el inicio y progresión de diversas enfermedades, sin embargo, también se ha revelado como un mecanismo inductor de senescencia, principalmente la inhibición del proteosoma y la inhibición de la autofagia, aunque esta última ha generado controversia.

Por ello el objetivo de este trabajo fue verificar si es posible inducir senescencia mediante la inhibición de la autofagia. 
Nuestros resultados muestran que spautin-1 inhibe la autofagia en los astrocitos. Así mismo, la proliferación disminuye significativamente por efecto del inhibidor.

Las células positivas al marcador de senescencia como el ensayo de ß-galactosidasa muestran un incremento a los 6 días, así como el inhibidor del ciclo celular p16. Con estos resultados se muestra que la inhibición de la autofagia induce senescencia en astrocitos primarios de rata. 


\section{Abstract}

Senescence is a phenomenon defined by a permanent growth arrest as a response to damage or stress, it has been mainly related to aging and the diseases associated to this process. However, recently it has been demonstrated the participation of senescent cells during development, where the senescence stimuli are not stress dependent.

The role of senescent cells in age-related neurodegenerative diseases has become a topic of increasing interest in the past few years due to the increasing number of people who suffer from these diseases.

Astrocytes are the most numerous cells in the brain, thus they have received particular emphasis, since they are responsible for homeostasis in the brain, so that the loss of their functions by acquiring the senescent phenotype, represents a problem for the tissue microenvironment, which could lead to neurodegeneration.

In the central nervous system, loss of proteostasis has been associated to the origin and progression of many diseases, however, it has also been revealed as a triggering mechanism for senescence, such as proteasome inhibition and autophagy inhibition, although the last one is still under debate.

Thus, the aim of this work was to verify if it is possible to induce senescence through autophagy inhibition.

Our results show that spautin-1 inhibits autophagy in the astrocytes. Also, we observed that Spautin-1 has a serious effect on astrocyte proliferation rates. 
On this regard, senescence markers such as SA B-galactosidase show an increasing number of senescent cells at 6 days of treatment and also the levels of the cell cycle inhibitor protein $\mathrm{p} 16$. With this results, we demonstrate that autophagy inhibition leads to senescence in primary cultured rat astrocytes. 


\section{Introducción}

\subsection{Envejecimiento}

El envejecimiento es un fenómeno caracterizado por el deterioro gradual, progresivo e irreversible de un organismo a lo largo del tiempo (Muller, 2009; Rajawat et al., 2009). Existen diversas teorías para explicar el envejecimiento, entre ellas se encuentran las que sugieren que es un proceso genéticamente establecido (Finch y Tanzi, 1997). Por otro lado, las teorías estocásticas consideran que existen varios factores que contribuyen al envejecimiento, tales como el daño al DNA y la incapacidad para repararlo, daño a tejidos u organelos celulares por Especies Reactivas de Oxígeno (ERO) (Harman, 1956) y radicales libres, entrecruzamiento de proteínas e incapacidad de los mecanismos celulares para remover tanto estructuras como organelos dañados. La suma de esos factores y el daño acumulado que causan, provocaría en última instancia el envejecimiento. Cabe señalar que estas teorías no son mutuamente excluyentes (Muller, 2009).

De forma más reciente se ha propuesto que el deterioro durante el envejecimiento se modifica por un conjunto de factores externos conocidos como "exposoma", esta teoría sugiere que el tiempo y la calidad de vida son dependientes del medio ambiente, de la nutrición e incluso las infecciones a las que el organismo ha sido expuesto, ello modifica el estado redox y modula la expresión de genes del individuo y, por lo tanto, el proceso de envejecimiento (Jones, 2015). 


\subsection{Senescencia.}

Parte del deterioro del organismo durante el envejecimiento es originado por la prevalencia de células senescentes ( Lopez-Otin et al., 2013; Bigagli et al., 2015). La senescencia celular es un estado donde las células se mantienen metabólicamente activas, y se caracteriza por la detención permanente del ciclo celular y cambios en la expresión de genes (Muller, 2009). Este fenómeno puede ser catalogado de acuerdo a su mecanismo de inducción como senescencia replicativa (SR) y senescencia prematura inducida por estrés (SIPS por sus siglas en inglés). La SR fue descrita por Hayflick en los 60's y corresponde a un estado alcanzado por la célula cuando llega a su máxima capacidad replicativa y se relaciona con el acortamiento de los telómeros generado tras cada replicación del DNA (Hayflick y Moorhead, 1961; Hayflick, 1965). La senescencia prematura inducida por estrés, SIPS, se llama así porque las células detienen su ciclo celular como respuesta a un estrés, pero sin haber alcanzado su máxima capacidad proliferativa. Se ha sugerido que la SIPS pudiera ser un mecanismo antitumoral en respuesta al estrés oncogénico, estrés que puede derivar en la transformación de la célula y culminar con la formación de un tumor, o bien en respuesta a distintos tipos de estrés y/o daño como pueden ser estrés oxidante, inhibición de la autofagia o inhibición del proteosoma. Estos últimos se encuentran ligados a la proteostasis, por lo que un desbalance de proteínas mal plegadas genera agregados proteínicos como los observados en diversas enfermedades neurodegenerativas ( Torres et al., 2006; Lopez-Diazguerrero et al., 2006; Young et al., 2009; Rodier y Campisi, 2011; Kang et 
al., 2011). De esta forma la senescencia podría ser catalogada como un mecanismo de rescate celular, por otro lado, la senescencia celular tiene funciones fisiológicas. Por ejemplo, se ha reportado su participación en el desarrollo embrionario como células señalizadoras (Storer et al., 2013). También participan en la reparación de heridas y en la regeneración de tejidos (Davalos et al., 2010; Demaria et al., 2014).

Las células senescentes presentan una serie de características, como son la detención permanente del ciclo celular, la formación de foci heterocromáticos (SAFH), la sobreexpresión de la enzima ß-galactosidasa, una serie de cambios morfológicos que incluyen un aumento de tamaño en la célula, (Rodier y Campisi, 2011).

Sin duda una de las características más representativas de este fenómeno celular es el SASP, que consiste en la secreción de diversos factores de crecimiento, citocinas, quimiocinas e incluso radicales libres al medio, el fenotipo secretor asociado a la senescencia o SASP por sus siglas en inglés, cuya función ha sido relacionada al proceso de eliminación de estas células, atrayendo al sistema inmune y propiciando que sean removidas del tejido en el que se encuentren. Sin embargo, conforme avanza la edad y con el deterioro natural del sistema inmune, las células senescentes se acumulan y dañan el tejido. ( Rodier y Campisi, 2011; Laberge et al., 2012; Lopez-Otin et al., 2013; Bigagli et al., 2015). 


\subsection{Importancia de la senescencia.}

A pesar de que el papel central de las células senescentes en el organismo aun no queda claro del todo, se podrían definir tres momentos importantes con diferente función (Triana-Martinez et al., 2016). El primero de ellos es durante el desarrollo embrionario donde las células senescentes se ubican principalmente en regiones donde se inicia el crecimiento de una extremidad por lo cual parecen señalizar, por medio del SASP, la proliferación de las células circundantes y con ello dar forma y volumen al tejido de dicha extremidad. En el momento en el que concluyen con su función las células senescentes son eliminadas por el sistema inmune valiéndose nuevamente del SASP para atraer a las células del sistema inmune (Storer et al., 2013). El segundo es la senescencia como un mecanismo de respuesta a un daño, es decir, si se genera un daño en un tejido, puede inducir la aparición de células senescentes. Las células senescentes pueden contribuir en la reparación del tejido mediando procesos como la remodelación de la matriz extracelular, proliferación y el reclutamiento del sistema inmune para fagocitar los restos de células necróticas 0 bien células que murieron por apoptosis (Davalos et al., 2010; Demaria et al., 2014). El tercer rol de las células senescentes tiene que ver con su acumulación dentro de un tejido lo que se asocia con el decaimiento del sistema inmune relacionado a un estado patológico o bien con el envejecimiento (Freund et al., 2010). El SASP secretado por las células senescentes afecta el microambiente del tejido, modificándolo y en ocasiones afectando a las células vecinas incluso fomentando la 
aparición de enfermedades asociadas a la edad (Lopez-Otin et al., 2013; Bigagli et al., 2015).

\subsection{Astrocitos y homeostasis del tejido nervioso.}

Uno de los tejidos que se afecta de forma notoria en el envejecimiento es el cerebro, y el deterioro del sistema nervioso suele mostrar efectos muy evidentes e incapacitantes en el individuo (Chinta et al., 2014). Gran parte del correcto funcionamiento del cerebro se debe a los astrocitos que representan poco más del $50 \%$ del total celular de la corteza cerebral y cumplen funciones relevantes como brindar soporte a las neuronas, modular la excitabilidad y función sináptica, además de proveer a las neuronas de las enzimas antioxidantes que no son capaces de sintetizar, por lo que se puede decir que el estado redox de las neuronas depende de los astrocitos ( Sofroniew y Vinters, 2010; Bitto et al., 2010; Chinta et al., 2014; Alarcon-Aguilar et al., 2014; Bigagli et al., 2015). Ante cualquier deterioro del tejido nervioso, ya sea en situaciones de lesión neuronal, enfermedad o envejecimiento, la glía posee la capacidad de responder experimentando cambios morfológicos y funcionales de manera gradual y estereotípica, acompañados por la producción de citocinas pro-inflamatorias, lo que se denomina como gliosis reactiva (Ting et al., 2009). Sin embargo, se ha demostrado que los astrocitos en cultivo pueden entrar en senescencia como respuesta a distintos tipos de estrés como el oxidante, o por inhibición del proteosoma (Pertusa et al., 2007; Bitto et al., 2010; Bhat et al., 2012). Por lo que se ha sugerido que durante el envejecimiento pudiera haber una acumulación de astrocitos senescentes y que el SASP secretado por éstos fomenta 
la neuro-inflamación, característica de diversas enfermedades neurodegenerativas; además se ha pensado que también participe en el declive de la función motora y cognitiva asociada a la edad y se ha reportado la presencia de astrocitos senescentes en cerebros de pacientes con enfermedades neurodegenerativas como el Alzheimer (Bitto et al., 2010; Salminen et al., 2011).

\subsection{Autofagia y control de la proteostasis.}

El término proteostasis hace referencia al mantenimiento de todas las proteínas en su conformación, concentración y ubicación requerida dentro de la célula, sumado el balance entre síntesis y degradación de las mismas ( Roth y Balch, 2011; Braselmann et al., 2013). Este estado es sin duda importante para el correcto funcionamiento de las células ya que la mayoría de los procesos son ejecutado por proteínas, por lo que si éstas no tienen el plegamiento adecuado su función se verá disminuida o anulada, generando conflictos en la ejecución de cualquier proceso (Roth y Balch, 2011; Lopez-Otin et al., 2013).

La autofagia es un proceso fundamental en el mantenimiento de la proteostasis presente en las células eucariontes, este proceso se refiere a la degradación de componentes celulares por la vía lisosomal. Durante la autofagia, mayoritariamente se degradan proteínas de vida media larga, agregados incluso organelos completos, con la ventaja de que los componentes pueden ser reutilizados por la célula, es decir, es un mecanismo que se encarga de la de degradación y reciclaje de componentes celulares (Rajawat et al., 2009; Young et al., 2009; Kang et al., 2011; Castro, 2012). 
Hasta el momento se han descrito tres mecanismos de autofagia: la autofagia mediada por chaperonas, la microautofagia y la macroautofagia.

La autofagia mediada por chaperonas consiste en degradar determinadas proteínas que, al estar mal plegadas, exponen una secuencia de aminoácidos específica (KFERQ) la cual es reconocida por una proteína chaperona denominada HSC70 que junto con las co-chaperonas HIP, HOP, BAG-1, HSP40 y HSP90 transportan a la proteína al lisosoma permiten la interacción con el receptor LAMP-2A ubicado en la membrana del lisosoma. La activación de dicho receptor con sus subunidades permite la formación de un poro mediante el cual la proteína marcada es introducida para ser degradada. Cuando la proteína mal plegada entra al organelo, las proteínas que ayudaron al proceso son liberadas para poder volver a unirse a otra secuencia KFERQ si se requiere en el citosol (Castro, 2012; Cuervo y Wong, 2014; Valdor et al., 2014).

Por otro lado, la microautofagia es un proceso por el cual las proteínas son directamente endocitadas por el lisosoma con mecanismos aún desconocidos. A la fecha tampoco se reconoce alguna secuencia particular de aminoácidos o las características que debe tener la proteína para que pueda ser reconocida por el lisosoma y desencadenar dicho proceso (Castro, 2012; Li et al., 2012; Cuervo y Macian, 2014).

Finalmente, la macroautofagia, a la que de ahora en adelante haremos referencia cuando se utilice el término autofagia, es distinta de las dos anteriores porque se generan vesículas a partir de membranas (denominadas fagóforos o membranas de 
aislamiento) que en el citoplasma empiezan a elongarse para cubrir el material citoplásmico que va a ser degradado. Cuando el fagóforo rodea por completo las proteínas, agregados u organelos que van a ser degradados se cierra para formar una vesícula conocida como autofagosoma, la cual eventualmente se fusiona con un lisosoma para degradar su contenido.

Se distinguen entonces 4 etapas en el proceso (Chen y Klionsky, 2011; Tanida, 2011). La primera es la iniciación o inducción, que empieza cuando se forma el complejo ULK constituido por ATG13, FIP200 y ATG101. Bajo condiciones normales de nutrientes, ULK se encuentra fosforilado por TORC1, pero cuando hay estímulos para iniciar la autofagia, TORC1 se inactiva y se disocia de ULK y este se autofosforila en las subunidades FIP200 y ATG13. Posteriormente se reclutan los fosfolípidos y proteínas para la formación del autofagosoma. Este proceso es mediado por la activación del complejo VPS34 (VPS34, BECN1 y VPS15) el cual requiere ser fosforilado por el complejo ULK (Castro, 2012; Schneider y Cuervo, 2014).

La segunda etapa se puede definir como elongación o expansión. Es aquí donde se incorporan los fosfolípidos al fagóforo provenientes del retículo endoplásmico, membrana externa de la mitocondria o bien de vesículas completas (Cuervo, 2010) y para esto se requieren de dos sistemas de conjugación tipo ubiquitina: el primero es ATG12 unido covalentemente a ATG5 y el segundo es LC3 (o ATG8) que se une a fosfatidiletanolamina (PE). Dichas conjugaciones son catalizadas por proteínas de la famila de ATG's que tienen actividad de ubiquitin ligasas E1 (ATG7, común para los 
dos sistemas) y E2 (ATG10 para el primer mecanismo y ATG3 para el segundo). Antes de que LC3 sea conjugado o "lipidado" con PE tiene que ser escindido por Atg4 que funciona como una proteasa, dando lugar a LC3-I. Después de que LC3-I es lipidado con PE se denomina LC3-II y es entonces cuando se puede asociar a la membrana del fagóforo. Un dato importante es que LC3-II cambia su movilidad electroforética lo que permite que sea identificado fácilmente en un ensayo de Western-Blot como un marcador de autofagia. La lipidación de LC3-I es dependiente del complejo formado por ATG12, ATG5 y ATG16 (Tanida, 2011; Castro, 2012; Kiriyama \& Nochi, 2015).

La tercera etapa refiere a la maduración del autofagosoma que consiste en cerrar el fagóforo para encapsular por completo a las proteínas u organelos a degradar y la escisión de LC3-II de la membrana externa del fagóforo por ATG4B.

Finalmente, la etapa cuatro consiste en la fusión del autofagosoma con el lisosoma para dar lugar al autofagolisosoma y a partir de ese momento inicia la degradación del contenido del autofagosoma (Tanida, 2011; Kiriyama y Nochi, 2015).

\subsection{Pérdida de la proteostasis y su relación con la senescencia.}

La proteostasis juega un papel fundamental en la patogénesis de varias enfermedades, particularmente las neurodegenerativas. Esto se debe a que el desbalance del equilibrio respecto a las proteínas mal plegadas puede generar agregados proteínicos, lipofuscinas y otros agregados derivados de la oxidación de proteínas que dificultan el flujo de información en la célula, generando o extendiendo 
el daño oxidante, mismo que la célula puede interpretar como un mecanismo para inducir senescencia (Rajawat et al., 2009; Young et al., 2009; Kang et al., 2011; Blagosklonny, 2013).

El daño generado por la disfunción de la autofagia en enfermedades neurodegenerativas es evidente, sin embargo, si a este esquema se incluye la presencia de células que adquieren el fenotipo senescente debido a la alteración del equilibrio proteostático el panorama es mucho peor. La presencia de células senescentes en una enfermedad neurodegenerativa agrava en gran medida su progresión, dado que el SASP secretado por dichas células puede acelerar la neurodegeneración debido a la inflamación en el tejido y al mismo tiempo produciendo un mayor número de células senescentes que incrementan la cantidad de secreciones inflamatorias y por lo tanto perpetúan el daño (Alarcon-Aguilar et al., 2014; Campisi y Robert, 2014; Chinta et al., 2014; Perluigi et al., 2015; Tramutola et al., 2015).

\subsection{Spautin-1 (SP-1)}

Con todo lo anterior podría suponerse que la inhibición de la autofagia induciría la senescencia celular de manera prematura, sin embargo, existen resultados contradictorios, y en el caso de los astrocitos aún no existe ningún estudio al respecto. 
Para el estudio de cualquier mecanismo molecular, en este caso la autofagia, es importante ya sea inhibir o bien incrementar la actividad del proceso que se desea estudiar para denotar la relevancia de éste dentro de la célula.

Se han descrito varios inhibidores de la autofagia, pero uno de los más específicos es una molécula denominada Spautin-1. Esta molécula interactúa con dos proteínas: USP13 y USP10, mismas que funcionan como deubiquitinasas de la subunidad BECN1 del complejo VPS34. Cuando el complejo es liberado del complejo ULK y se activa, la subunidad BECN1 es susceptible a ser ubiquitinada por lo que la actividad de USP13 y USP10 es fundamental para que la autofagia se lleve a cabo, de lo contrario el complejo VPS34 es degradado. Spautin-1 ha sido evaluado como un inhibidor muy potente de la autofagia y es de ahí de donde obtiene su nombre "SPecific AUTophagy INhibitor-1" (Liu et al., 2011; Shao et al., 2014; Xiao et al., 2016).

\section{Antecedentes}

La proteostasis ha sido considerada como un mecanismo que puede regular la entrada a senescencia. Se ha demostrado que otros procesos que modifican la proteostasis, como la inhibición parcial del proteosoma, son mecanismos que inducen la entrada a senescencia (Torres et al., 2006; Maciel-Baron et al., 2016), sin embargo, el papel de la autofagia en relación con la inducción de senescencia es todavía controversial. 
El uso de algunos compuestos químicos como la rapamicina, un inhibidor de mTOR que activa la autofagia, ha derivado en múltiples estudios sobre los efectos sobre la extensión del tiempo de vida en organismos como levaduras (Alvers et al., 2009), moscas de fruta (Scialo et al., 2015) y roedores (Neff et al., 2013; Bitto et al., 2016). Pero también se ha evaluado su efecto sobre la inducción de senescencia y algunos estudios demuestran que la rapamicina retrasa o impide la inducción de senescencia en cultivos celulares (Demidenko et al., 2009; Pospelova et al., 2012; Pospelova et al., 2013). Recientemente se demostró que la autofagia es fundamental para evadir la senescencia en células troncales musculares (también llamadas células satelitales), permitiendo de esta forma mantener el tejido funcional, contrario a lo que pasa en el envejecimiento donde la autofagia basal disminuye y el tejido muscular se ve comprometido (Garcia-Prat et al., 2016).

En otra instancia, Kang y colaboradores en 2011 se dieron a la tarea de silenciar la expresión de proteínas asociadas a la autofagia y como resultado encontraron que el hecho de afectar este proceso induce senescencia en fibroblastos de cultivo primario humano (Kang et al., 2011).

Por otro lado, cuando se pensaba que la autofagia era un proceso clave para evitar la entrada a senescencia, surgieron resultados controversiales cuando al someter a distintos tipos celulares a estrés oncogénico mediante la sobreexpresión de la proteína Ras, se detectó que parte de la lámina nuclear, en forma particular la lámina B1, era degradada vía autofagia comprometiendo de esta forma la proliferación de las células y fomentando la entrada a un estado senescente (Shimi et al., 2011; Dou 
et al., 2015; Dou, 2016). Esto corresponde con lo reportado por Young y colaboradores en 2009, donde demostraron que la actividad de la autofagia incrementa al inducirse la senescencia y que al inhibirla no se alcanzaba este estado celular (Young et al., 2009).

Si bien el papel de la autofagia en la senescencia es controversial, casi todos los estudios se han realizado en fibroblastos y no hay reportes en donde se haya evaluado en astrocitos por lo que en el presente trabajo se estudió el efecto de la inhibición de la autofagia en la inducción de senescencia en dicho modelo celular. En este caso se utilizó el inhibidor Spautin-1 y se evaluó su efecto a distintas concentraciones.

\section{Justificación}

En nuestro país la CONAPO estima que en el año 2050 el $22.6 \%$ de la población en México será mayor a 65 años, contrastando con el 10.8\% que se contabilizó en 2014. Por ello, el estudio del envejecimiento se ha convertido en un tema de suma importancia, ya que durante el envejecimiento incrementa el riesgo de los individuos a padecer enfermedades como cáncer, diabetes, enfermedades cardiovasculares, enfermedades neurodegenerativas, entre otras dificultades motoras y cognitivas que se presentan con regularidad (Lopez-Otin et al., 2013Kennedy et al., 2014).

Aunque el estudio y comprensión de las enfermedades ha permitido desarrollar mecanismos para contrarrestarlas y elevar de esta forma la esperanza de vida en la 
sociedad, el hecho de incrementar el tiempo de vida de la población no siempre va acompañado de una buena calidad de vida en edades avanzadas.

Por otro lado, la senescencia es un proceso que influye en el desarrollo de enfermedades asociadas al envejecimiento (enfermedades neurodegenerativas, cáncer) por lo que es adecuado comprender el papel de la autofagia como mecanismo inductor de la senescencia y de esta forma lograr identificar posibles blancos terapéuticos que permitan ofrecer una mejor calidad de vida a la sociedad.

\section{Pregunta de Investigación}

¿Será posible inducir senescencia en astrocitos de cultivo primario de rata inhibiendo la autofagia?

\section{Hipótesis}

La autofagia es un proceso celular que se encarga de la degradación y reciclaje de componentes celulares en condiciones de privación de nutrientes, degradación de organelos dañados y agregados proteínicos para permitirle a las células sobrevivir a estas condiciones de estrés. Por lo que se espera que al inhibir este proceso se induzca la senescencia celular mediante mecanismos moleculares relacionados a la acumulación de daño en los astrocitos. 


\section{Objetivo general}

Evaluar y caracterizar la inhibición de la autofagia como mecanismo inductor de senescencia en cultivo primario de astrocitos de rata.

\section{Objetivos particulares}

- Determinar la concentración de SP-1 necesaria para abatir la proliferación celular de astrocitos de cultivo primario de rata.

- Determinar efecto de SP-1 sobre la autofagia de los astrocitos primarios de rata.

- Evaluar marcadores clásicos de senescencia a 3 y 6 días de tratamiento con SP-1.

\section{Material y Métodos}

\subsection{Material biológico (animales)}

Se utilizaron ratas de la cepa Wistar neonatas de 4 a 7 días de nacidas. Los animales fueron obtenidos del bioterio de la Universidad Autónoma Metropolitana Unidad Iztapalapa, donde fueron mantenidos en condiciones estándar (temperatura ambiente (TA), ciclo de luz normal y las madres de los neonatos contaron con acceso libre de comida y agua). El manejo de los animales fue acorde a lo establecido en la "Guía para el cuidado de los animales de laboratorio" editado por la Academia Mexicana de Medicina, y la NOM 062-ZOO-1999. 
En total fueron empleados 24 animales para este trabajo.

\subsection{Obtención del cultivo primario de astrocitos de rata.}

El cultivo primario de astrocitos se obtuvo de la corteza cerebral de los animales con base en el procedimiento reportado en el laboratorio (Alarcón-Aguilar et al., 2014) Una vez sacrificadas las ratas, se extrajo el cerebro de la parte dorsal y se colocó en un tubo de $50 \mathrm{~mL}$ con PBS (Solución salina amortiguada por fosfatos). Ya dentro de la campana de flujo laminar, el cerebro se colocó en una caja Petri de $10 \mathrm{~cm}$ de diámetro y se removió el PBS. Se cortó el cerebro en trozos pequeños con un bisturí. Posteriormente, la suspensión se vertió en un tubo que contenía $10 \mathrm{~mL}$ de medio de cultivo (MEM (Medio mínimo esencial), 10\% SFB (Suero fetal bovino), 1\% de antibiótico, $0.15 \%$ de glucosa y $0.11 \%$ de glutamina) y se resuspendió vigorosamente 10 veces con una micropipeta de $5 \mathrm{~mL}$. Los trozos grandes de tejido se retiraron con la ayuda de una pipeta Pasteur. El resto de la suspensión se filtró a través de un filtro con poros de $100 \mu \mathrm{m}$ y se añadió medio de cultivo nuevo hasta un volumen final de $10 \mathrm{~mL}$. Esta suspensión final se sembró en 2 cajas de Petri de $10 \mathrm{~cm}$ de diámetro y se incubó a $37^{\circ} \mathrm{C}$ y $5 \%$ de $\mathrm{CO}_{2}$. El cultivo se mantuvo bajo esas condiciones $24 \mathrm{~h}$, posteriormente se cambió el medio de cultivo por medio nuevo.

A partir de este momento, los astrocitos se mantuvieron en las condiciones de incubación antes mencionadas y bajo el mismo régimen de medio suplementado con SFB, antibióico, glucosa y glutamina. El cambio de medio de cultivo se realizó cada 3 días y cuando las cajas llegaban a confluencia las células eran lavadas con PBS, se agregaba $1 \mathrm{~mL}$ de tripsina al $0.1 \%$ para despegarlas, posteriormente se inactivaba 
con $2 \mathrm{~mL}$ de medio de cultivo fresco y se resuspendían en $10 \mathrm{~mL}$ de medio en un tubo falcon de $15 \mathrm{~mL}$ para contarse (véase sección 10.5) y resembrarse según era requerido.

\subsection{Caracterización del cultivo}

El cultivo se caracterizó con GFAP (Proteína Ácida Fibrilar Glial) por medio de una inmunofluorescencia para garantizar que las células obtenidas eran realmente astrocitos. Para este efecto se sembraron $2 \times 10^{5}$ células en cubreobjetos y se fijaron con formalina neutra (formaldehido al 4\% en PBS) durante 10 min, posteriormente realizaron 2 lavados con PBS para retirar el exceso de formalina y se incubaron con bloqueador universal de proteínas $\left(B i o G e n e x^{\circledR}\right)$ durante 10 min. Posteriormente se lavaron dos veces con PBS-T (PBS-Tween 20 0.1\%) y se incubaron con $200 \mu \mathrm{L}$ de anticuerpo primario anti-GFAP (Santa Cruz Biotechnology ${ }^{\circledR}$ ) en proporción 1:200 disuelto en PBS-T durante $1.5 \mathrm{~h}$ a TA. Posteriormente se realizaron 3 lavados con PBS-T en agitación durante $5 \mathrm{~min}$, acto seguido se agregaron $200 \mu \mathrm{L}$ de un anticuerpo secundario Alexa Fluor ${ }^{\circledR} 594$ anti-ratón dilución 1:500 y se incubó durante 1 hora en oscuridad a temperatura ambiente. Se montaron las muestras sobre un portaobjetos con solución de montaje con DAPI (Sigma-Aldrich $\left.{ }^{\circledR}\right)$ para teñir los núcleos, las laminillas se sellaron, se almacenaron en oscuridad y refrigeración hasta ser examinadas en el microscopio Carl Zeiss modelo LSM 780 NLO multifotónico. 


\subsection{Tratamientos con Spautin-1}

Para los tratamientos con Spautin-1 (Sigma-Aldrich ${ }^{\circledR}$ ) se preparó un stock $10 \mathrm{mM}$ disuelto en DMSO (Dimetilsulfóxido, Sigma-Aldrich ${ }^{\circledR}$ ), a partir del cual se derivaron los tratamientos para los astrocitos a concentraciones de 2, 5, 10 y $20 \mu \mathrm{M}$. Todas las concentraciones fueron evaluadas a 3 y 6 días para ensayos de SA B-gal, inmunofluorescencia y western-blot.

\subsection{Curvas de proliferación}

Para determinar la proliferación del cultivo bajo las condiciones establecidas se utilizaron dos métodos, el primero fue contando las células teñidas con azul tripano. Para ello las células fueron lavadas con PBS y despegadas con tripsina $0.1 \%$, se tomaron alícuotas de $20 \mu \mathrm{L}$ de la suspensión, dicha alícuota se mezcló con $20 \mu \mathrm{L}$ de azul tripano. La mezcla resultante fue resuspendida nuevamente y se tomó una alícuota de $10 \mu \mathrm{L}$ para posteriormente ser colocada en una cámara de Neubauer para ser observada en un microscopio óptico y realizar el conteo de 4 cuadrantes, de los cuales se calculó la media, $\dot{x}$.

El número de células se calculó mediante la ecuación:

$$
N=(\dot{x}) *(V){ }^{*}(2) *\left(10^{4}\right)
$$

Dónde: $\mathrm{N}$ = Número total de células

$V=$ Volumen total de la suspensión de células $(\mathrm{mL})$ 
Posteriormente se validó el conteo celular con el kit comercial CCK-8 ${ }^{\circledR}$ que es un ensayo de colorimetría que utiliza las deshidrogenasas disponibles en las células para transformar una sal soluble de tetrazolio en un compuesto de formazán color amarillo que puede ser evaluado por espectrofotometría. Así la cantidad de formazán generada es proporcional al número de células vivas. Esta prueba es mucho más sensible que otras sales de tetrazolio como el MTT (3-(4,5- dimetiltiazol-2-ilo)-2,5difeniltetrazol). Para dicho efecto se sembraron astrocitos en placas de 96 pozos, realizando una curva de calibración sembrando 2000, 4000, 8000, 10000, 16000 y 32000 células por pozo. Para los tratamientos se sembraron 10000 células por pozo.

Para el ensayo las células se lavaron con PBS y posteriormente se agregaron $100 \mu \mathrm{L}$ de medio con $10 \mu \mathrm{L}$ de $\mathrm{CCK}-8^{\circledR}$ disueltos en este (proporción 10:1). La placa fue incubada por $1 \mathrm{~h}$ en oscuridad para posteriormente realizar la lectura pertinente en el lector de ELISA H Reader $1^{\circledR}$ (HLAB) a una longitud de onda de $450 \mathrm{~nm}$. Las lecturas registradas fueron interpoladas mediante la ecuación de la recta obtenida en la gráfica generada de las lecturas de la curva de calibración.

Los resultados fueron obtenidos en número de células, pero fueron expresados en porcentaje para poder comparar ambas técnicas.

\subsection{Carbonilación de proteínas}

Las proteínas carboniladas son el resultado de diversas reacciones oxidantes, su estructura es dañada por los radicales libres originando un grupo carbonilo (aldehído 
o cetona) en las cadenas laterales de los aminoácidos, por lo tanto, son un marcador estándar del estrés oxidante.

Para este ensayo se sembraron $0.6 \times 10^{6}$ astrocitos en cajas Petri de $10 \mathrm{~cm}$, fue adicionado SP-1 a concentraciones 2, 5, 10 y $20 \mu \mathrm{M}$ y se extrajo proteína a los 3 y 6 días de tratamiento como se señala en el apartado 10.10 .

La concentración de proteínas carboniladas, se determinó mediante el empleo de la 2, 4 dinitrofenilhidrazina (DNP), donde los grupos carbonilos (aldehídos y cetonas) reaccionan con este compuesto formando fenilhidrazona precipitando en color amarillo.

Se preparó una solución stock de proteínas carboniladas adicionando $200 \mu \mathrm{L}$ de BSA (Albúmina sérica bovina) 10X y peróxido de hidrógeno $\left(\mathrm{H}_{2} \mathrm{O}_{2}\right) 11 \mathrm{M}$, seguido de la preparación de una curva:

\begin{tabular}{|c|c|c|c|c|}
\hline $\begin{array}{l}\text { Sol stock de } \\
\text { proteínas } \\
\text { carboniladas }\end{array}$ & Reactivo DNP & Incubar a TA & PBS & Volumen Total \\
\hline- & $10 \mu \mathrm{L}$ & \multirow{6}{*}{ Incubar 15 min } & $50 \mu \mathrm{L}$ & $60 \mu \mathrm{L}$ \\
\hline $20 \mu \mathrm{L}$ & $10 \mu \mathrm{L}$ & & $50 \mu \mathrm{L}$ & $80 \mu \mathrm{L}$ \\
\hline $40 \mu \mathrm{L}$ & $10 \mu \mathrm{L}$ & & $50 \mu \mathrm{L}$ & $100 \mu \mathrm{L}$ \\
\hline $80 \mu \mathrm{L}$ & $10 \mu \mathrm{L}$ & & $50 \mu \mathrm{L}$ & $140 \mu \mathrm{L}$ \\
\hline $160 \mu \mathrm{L}$ & $10 \mu \mathrm{L}$ & & $50 \mu \mathrm{L}$ & $220 \mu \mathrm{L}$ \\
\hline $320 \mu \mathrm{L}$ & $10 \mu \mathrm{L}$ & & $50 \mu \mathrm{L}$ & $360 \mu \mathrm{L}$ \\
\hline
\end{tabular}

Para realizar la cuantificación de proteínas carboniladas de las muestras se preparó como sigue: 


\begin{tabular}{|l|l|l|l|l|}
\hline Muestra & Reactivo DNP & & PBS & Volumen total \\
\hline $20 \mu \mathrm{L}$ & $10 \mu \mathrm{L}$ & Incubar $15 \mathrm{~min}$ & $50 \mu \mathrm{L}$ & $80 \mu \mathrm{L}$ \\
\hline
\end{tabular}

Posteriormente se determinó en cada tubo la absorbancia a $450 \mathrm{~nm}$ en el el lector de ELISA H Reader $1^{\circledR}(\mathrm{HLAB})$. Para calcular la concentración se interpoló la absorbancia de la muestra en las mediciones de la curva patrón, aplicando la ecuación de la recta: $\mathrm{X}=(\mathrm{Y}-\mathrm{b}) / \mathrm{m}$.

\subsection{Cyto-ID}

Como un parámetro para validar el efecto del SP-1 como inhibidor de autofagia se utilizó el kit Cyto-ID ${ }^{\circledR}$ (Enzo Life Sciences), el cual permite detectar la formación de autofagosomas en las células mediante fluorescencia. Para ello se sembraron $2 \times 10^{4}$ astrocitos por pozo en placas de 24 pozos, con los tratamientos señalados anteriormente además de un grupo con restricción de nutrientes por 24 h como control positivo para autofagia. Al finalizar los tratamientos de 3 y 6 días se retiró el medio y realizó un lavado con PBS para posteriormente colocar el Cyto-ID $1 \mu \mathrm{L}$ por $\mathrm{mL}$ de medio y junto con este y en la misma proporción se añadió Hoechst para la tinción de núcleos. Posteriormente se mantuvieron en una incubadora bajo condiciones estándar de temperatura y $\mathrm{CO}_{2}$ durante $30 \mathrm{~min}$. Las placas fueron evaluadas bajo un microscopio invertido de Fluorescencia Carl Zeiss y las imágenes fueron adquiridas con ayuda del software $Z E N^{\circledR}$ de Carl Zeiss. 


\subsection{Ensayo SA B-Gal}

Fueron sembrados $2 \times 10^{4}$ astrocitos en placas de 24 pozos y tratados con SP-1 a las distintas concentraciones evaluadas durante los periodos de tiempo estipulados anteriormente. Posteriormente se les retiró el medio de cultivo, seguido por dos lavados con PBS se fijaron con solución formaldehído al 3\% disuelto en PBS durante 15 min. Después se lavaron dos veces con PBS para retirar el exceso de solución de formaldehído y se incubaron a $37^{\circ} \mathrm{C}$ por una noche en la solución de tinción: $1 \mathrm{mg} / \mathrm{mL}$ 5-bromo-4-cloro-3-indol-ß-D-galactosidasa, buffer de ácido cítrico/fosfato $40 \mathrm{mM}(\mathrm{pH}$ 6.0), ferricianuro de potasio $5 \mathrm{mM}$, ferrocianuro de potasio $5 \mathrm{mM}, \mathrm{NaCl} 150 \mathrm{mM}$ y $\mathrm{MgCl}_{2} 2 \mathrm{mM}$. Para tomar las fotografías fue necesario realizar dos lavados con PBS para retirar la solución de tinción y evitar la sobretinción. Se contaron las células positivas al ensayo, para ello se consideraron 4 campos aleatorios y se contaron 300 células y se calculó el porcentaje de células teñidas para cada grupo experimental.

Se consideró que se había alcanzado la senescencia del cultivo cuando el porcentaje de células positivas a este ensayo fue mayor al $70 \%$.

\subsection{Inmunofluorescencias de p16 y B-gal.}

De forma similar a la caracterización de GFAP, fueron sembradas $2 \times 10^{5}$ células por cubreobjetos en placas de 6 pozos, se fijaron con formalina neutra durante 10 min, posteriormente se incubaron con bloqueador universal de proteínas (BioGenex ${ }^{\circledR}$ ) durante $10 \mathrm{~min}$, después se incubaron con $200 \mu \mathrm{L}$ de anticuerpo primario anti-p16 (Santa Cruz Biotechnology ${ }^{\circledR}$ ) dilución 1:200 en PBS-T durante 1.5 h a TA, 
posteriormente se realizaron 3 lavados en agitación con PBS-T para ser incubado con $200 \mu \mathrm{L}$ del anticuerpo primario de ß-gal o Glb-1 (Abcam) dilución 1:500 en PBST durante $1.5 \mathrm{~h}$ seguido de la incubación con $200 \mu \mathrm{L}$ de anticuerpos secundarios Alexa Fluor ${ }^{\circledR} 488$ anti-conejo y Alexa Fluor ${ }^{\circledR} 594$ anti-ratón en dilución 1:500 en PBS-T, uno a la vez durante $2 \mathrm{~h}$ en oscuridad a TA con 3 lavados en oscuridad y agitación con PBS-Tween $0.1 \%$ entre cada uno y al final. Como último paso se montaron las muestras sobre un portaobjetos con solución de montaje con DAPI para teñir los núcleos, las laminillas fueron selladas y se mantuvieron en refrigeración hasta ser examinadas en el microscopio confocal Carl Zeiss modelo LSM 780 NLO multifotónico.

\subsection{Western-Blot}

Para cada experimento se emplearon por lo menos $1 \times 10^{6}$ astrocitos, los cuales se despegaron con gendarme y se re-suspendieron en buffer de lisis $(9 \mathrm{~mL}$ de solución M-PER, 1 mM PMSF (fluoruro de fenilmetilsulfonilo), $1 \mathrm{mM}$ DTT (ditiotrietol),1 pastilla de complete Roche ${ }^{\circledR}$ ). Los homogenados celulares se incubaron a $4^{\circ} \mathrm{C}$ durante 10 min y posteriormente se centrifugaron a $14000 \mathrm{rpm}$ a $4{ }^{\circ} \mathrm{C}$ durante $20 \mathrm{~min}$. La concentración de proteínas se determinó en el sobrenadante utilizando el reactivo comercial de Bradford (BioRad). Las proteínas en los lisados celulares se separaron en un gel SDS-PAGE de gradiente $4-20 \%$ (BioRad) a $90 \vee$ durante $1.5 \mathrm{~h}$ y posteriormente fueron transferidas a una membrana de PVDF (GE). Las membranas se bloquearon con TBS-Tween $0.1 \%$, $8 \%$ leche libre de grasa durante $1 \mathrm{~h}$, posteriormente se incubaron con el anticuerpo monoclonal respectivo durante $12 \mathrm{~h}$ 
en refrigeración y se lavaron con TBS-Tween para incubarse con el anticuerpo secundario conjugado con peroxidasa de rábano durante $1.5 \mathrm{~h}$. Las membranas se revelaron usando el estuche comercial supersignal chemiluminiscent, y se analizarán en un Gel Logic Kodak 1500 (Software Molecular Analyst). Se utilizaron los anticuerpos para p16, p21, p27, p53 (Santacruz Biotechnollogy ${ }^{\circledR}$ ) en dilución 1:1000 en TBS-T. Como control de carga se utilizó B-actina, para lo que se utilizó anticuerpo monoclonal elaborado y donado por el laboratorio del Dr. Jose Manuel Hernández Hernández del CINVESTAV.

\subsection{Análisis estadístico}

Cada experimento se realizó por triplicado en al menos tres eventos independientes. Los datos fueron sometidos a un análisis de varianza de una vía (One-Way ANOVA) complementaria con una prueba de comparaciones múltiples Tukey-Kramer y para el experimento de carbonilación de proteínas se utilizó la prueba de Bonferroni. Para

todos los análisis estadísticos se utilizó el software GraphPad Prism ${ }^{\circledR}$ y se manejó un nivel de probabilidad de $p<0.05$ como criterio mínimo de significancia. 


\section{Resultados}

\subsection{Caracterización del cultivo primario de astrocitos de rata.}

La caracterización del cultivo se realizó mediante inmunofluorescencia de la proteína GFAP (Proteína Ácida Fibrilar Glial) que es un componente del citoesqueleto (filamentos intermedios) de astrocitos, misma que no se encuentra en otros tipos celulares del tejido nervioso, por ello ha sido utilizada por numerosos grupos de investigación como marcador de astrocitos (Bitto et al., 2010; Bhat et al., 2012; Alarcon-Aguilar et al., 2014). Como se puede observar en la Figura 1, la inmunofluorescencia del cultivo resultó positivo a la expresión de dicha proteína con lo que se comprobó la existencia de los astrocitos, coincidiendo con lo reportado en la literatura respecto a la técnica para aislar este tipo celular.

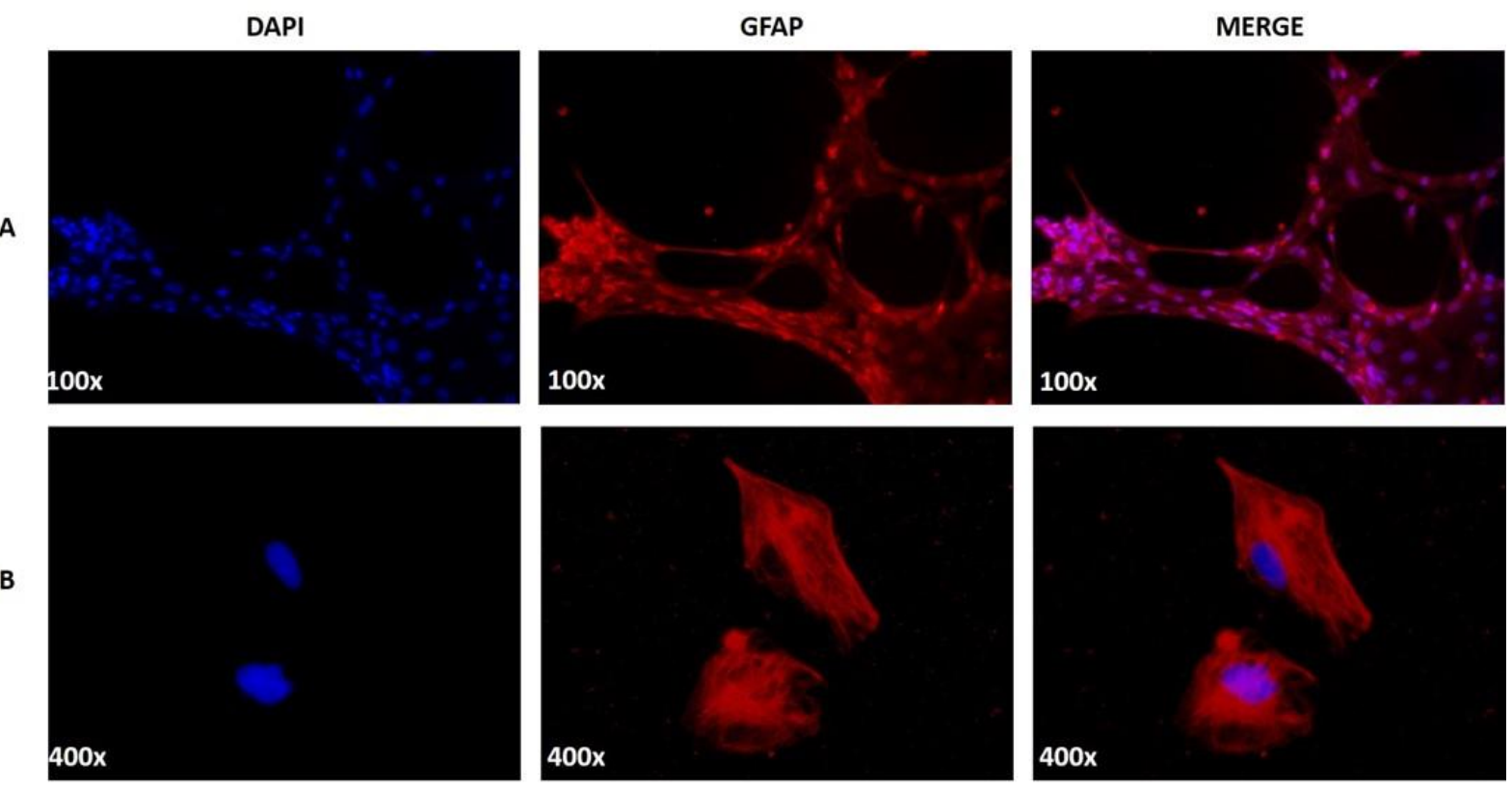

Figura 1. Inmunofluorescencia de GFAP. En la imagen se muestran las fluorescencias obtenidas de DAPI (azul) y GFAP (rojo) en canales separados además del merge del cultivo primario de astrocitos a $100 x(A)$ y $400 x(B)$. 


\subsection{Efecto de SP-1 sobre el cultivo primario de astrocitos de rata}

Dado que en la senescencia celular se da una inhibición de la proliferación y una vez que el cultivo fue caracterizado, el siguiente paso fue realizar pruebas con SP-1 para observar el comportamiento de la proliferación de los astrocitos con distintas concentraciones de SP-1.

En primera instancia se evaluó si existía un cambio en la morfología de los astrocitos en contacto con ésta molécula. Como se observa en la Figura 2, los astrocitos mantienen su morfología con respecto al control en las concentraciones de 2, 5 y 10 $\mu \mathrm{M}$, sin embargo, a la concentración de $20 \mu \mathrm{M}$ de SP-1 se puede constatar que existe un cambio en la morfología de las células, una baja notoria en la capacidad de proliferación puesto que se observa una diferencia en la confluencia a simple vista respecto al control, indicando que a esta concentración el inhibidor podía estar induciendo senescencia (por ello la baja confluencia) o bien teniendo un efecto citotóxico sobre el cultivo. 


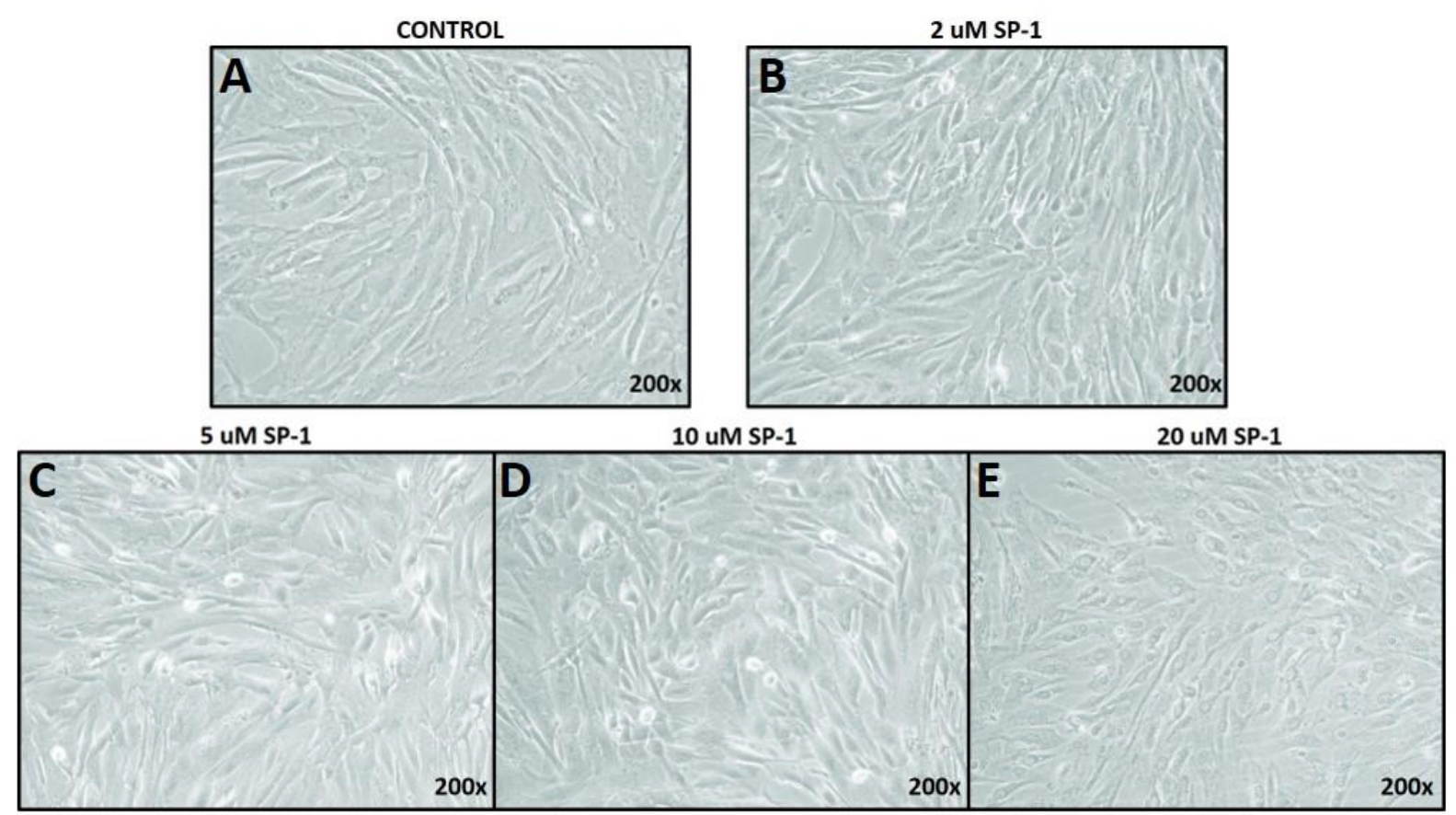

Figura 2. Micrografías del cultivo primario de astrocitos donde se observa la morfología del mismo en el grupo control (A) y con tratamientos de SP-1 a concentraciones $2 \mu \mathrm{M}$ (B), $5 \mu \mathrm{M}(\mathrm{C}), 10 \mu \mathrm{M}(\mathrm{D})$ y $20 \mu \mathrm{M}(\mathrm{E})$.

\subsubsection{Curvas de proliferación del cultivo primario con SP-1}

Para corroborar que en efecto la baja confluencia a la concentración más alta fuera ocasionada por el SP-1 se procedió a realizar los ensayos de proliferación. Estos ensayos fueron realizados por dos técnicas distintas para poder corroborar el efecto de SP-1 sobre la proliferación. El primero fue por conteo en cámara de Neubauer con tinción de azul tripano. Como se muestra en la Figura 3, la proliferación de los astrocitos disminuyó conforme aumentaba la concentración del inhibidor y prácticamente se abatió con la concentración de $20 \mu \mathrm{M}$, obteniendo un resultado similar, pero no tan contundente en la concentración de $10 \mu \mathrm{M}$. Ambas concentraciones con resultados significativamente diferentes respecto al control a los 
6 días. No así para las otras concentraciones que, aunque muestran una disminución en la proliferación, no resultan significativamente distintas del control a los 6 días.

Para validar los resultados obtenidos en este experimento se realizó un ensayo de proliferación con el kit CCK-8 ${ }^{\circledR}$ en donde se observó que, al igual que en el ensayo anterior, el efecto sobre la proliferación a las concentraciones de 10 y $20 \mu \mathrm{M}$ mostró una disminución significativa respecto al control a los 6 días. De manera interesante, las células tratadas con $5 \mu \mathrm{M}$ de SP-1 muestran valores similares a los del tratamiento con $10 \mu \mathrm{M}$. Nuevamente la concentración de $2 \mu \mathrm{M}$ no mostró diferencias significativas respecto al control. 


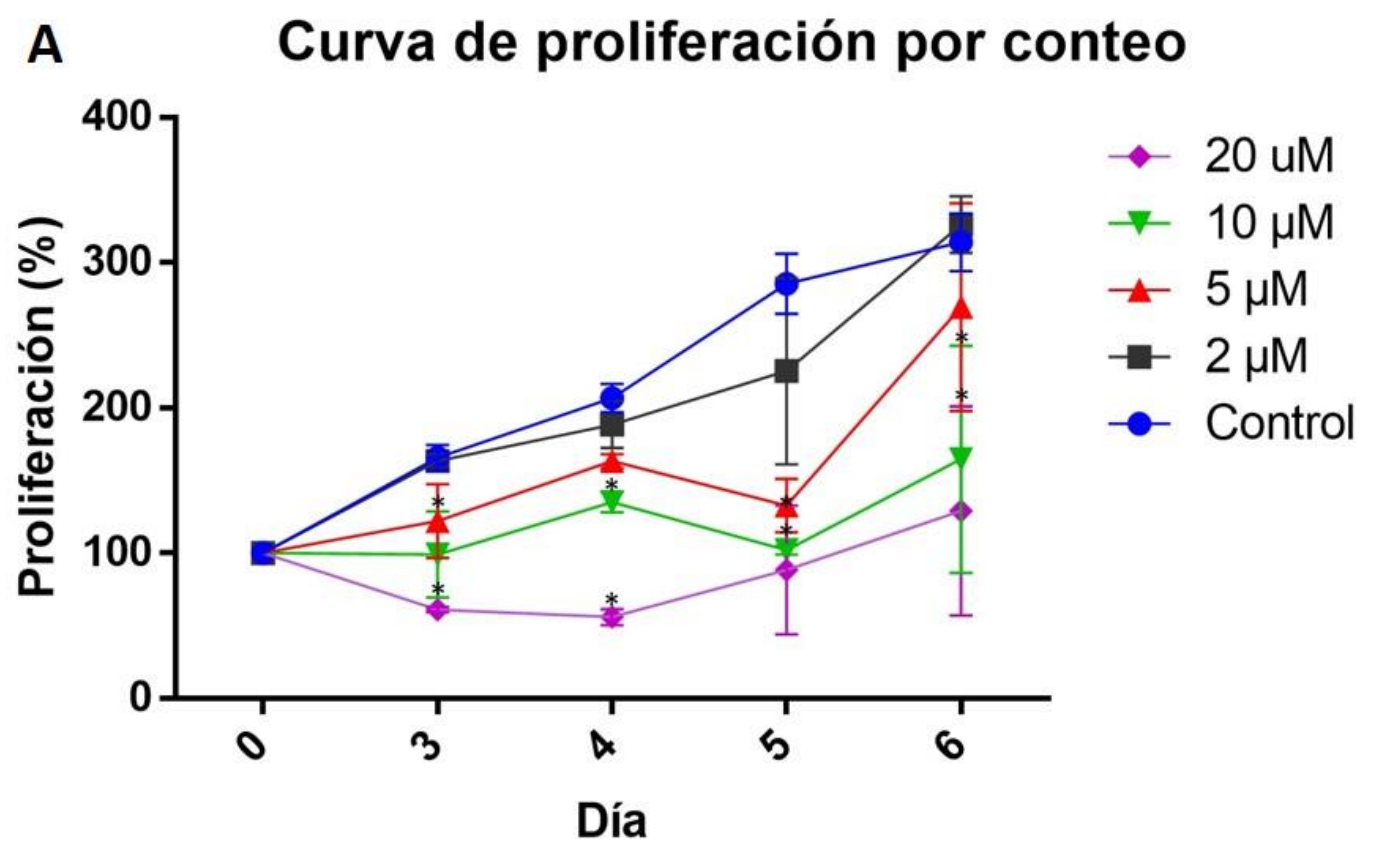

B Curva de proliferación CCK-8

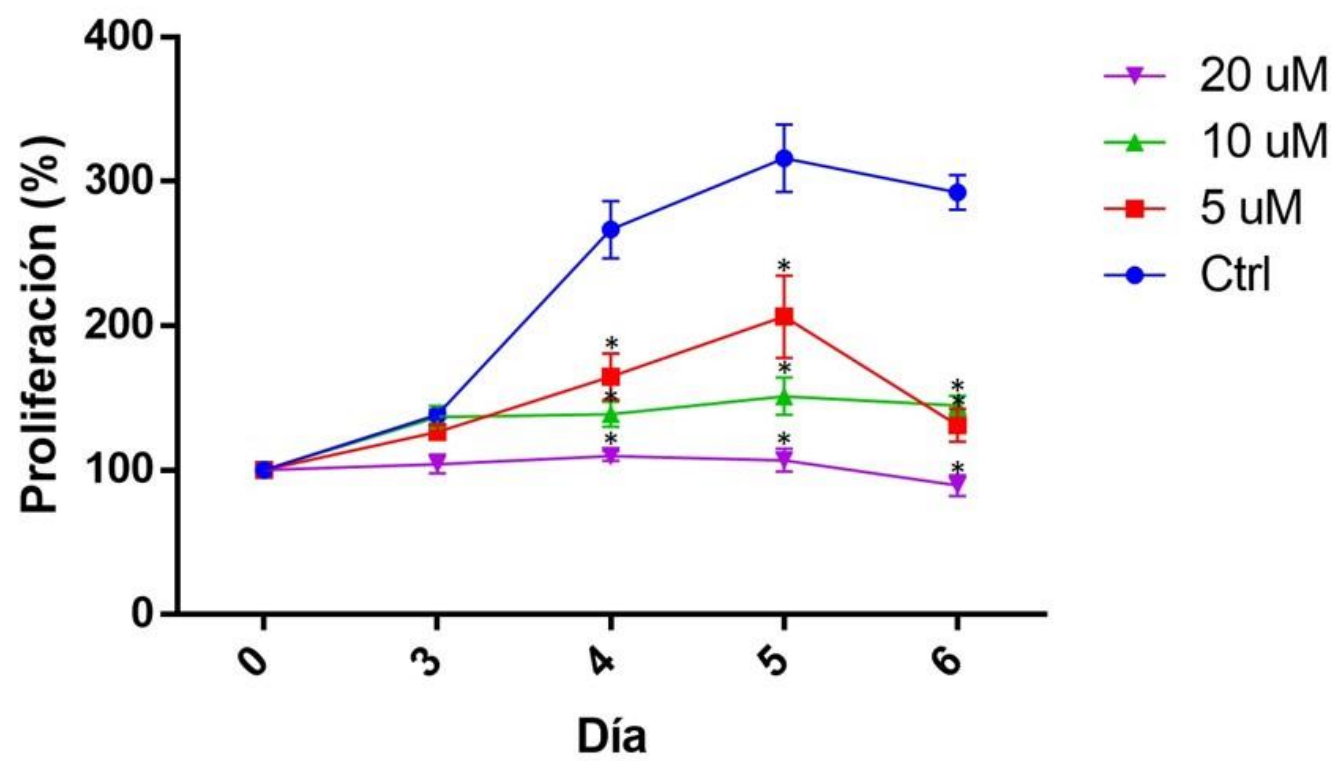

Figura 3. Gráficas de proliferación de astrocitos. En esta figura se muestran las gráficas de los ensayos de proliferación en porcentaje con SP-1 a distintas concentraciones evaluados por conteo con azul tripano (A) y con el kit CCK-8 (B). Se realizaron 3 experimentos independientes por triplicado.

- $p<0.05$ comparado con el control del dia de la evaluación. 


\subsubsection{Niveles de carbonilación de proteínas generados por SP-1}

Para verificar que en efecto los astrocitos a concentración de $20 \mu \mathrm{M}$ de SP-1 estaban más dañados que los tratados con las otras concentraciones, se realizó un ensayo para determinar la carbonilación de proteínas totales.

Como se observa en la Figura 4, la carbonilación de proteínas fue significativamente superior en todas las concentraciones a 3 y 6 días de tratamiento, con excepción de $2 \mu \mathrm{M}$ a 3 días, con respecto al control. De forma interesante, los niveles de carbonilación a la concentración de $20 \mu \mathrm{M}$ a 6 días de tratamiento son aproximadamente 10 veces más que el control.

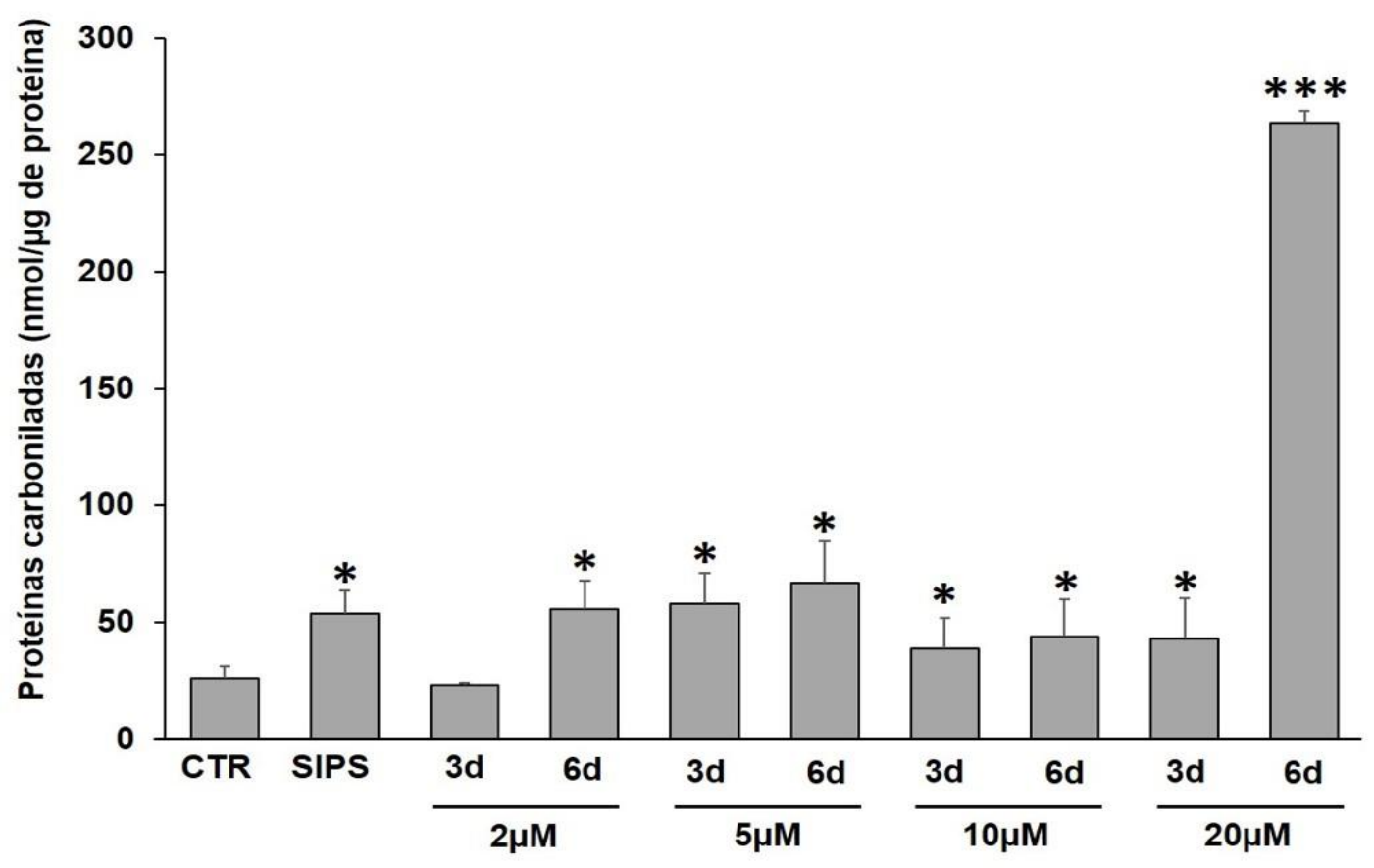

Figura 4. Gráfica de carbonilación de proteínas. En esta figura se muestra el nivel de carbonilación de proteínas generado por los tratamientos con SP-1 a las distintas concentraciones en 3 y 6 dias de tratamiento. Se realizaron 3 experimentos independientes por triplicado.

* $\mathrm{p}<0.05 \mathrm{y}$ ** $\mathrm{p}<0.001$ comparado con el control. 


\subsubsection{Ensayo de detección de autofagia con Cyto-ID}

Una vez que se evaluó que el tratamiento con SP-1 si mostraba un efecto sobre la proliferación de los astrocitos, se procedió a validar lo que sucedía con la autofagia, proceso en el que impacta directamente dicha molécula. Se utilizó el kit de Cyto-ID para valorar la formación de autofagosomas en los astrocitos con las distintas concentraciones de SP-1. En las Figuras 5 y 6 se puede observar que la formación de autofagosomas fue prácticamente nula en todas de las concentraciones de SP-1 empleadas, al comparar los astrocitos tratados contra el control positivo de autofagia, que corresponde a los astrocitos con restricción de nutrientes por 24 h, e incluso con el de la autofagia basal del control sin SP-1. La inhibición de la autofagia se observó tanto a los 3 como a los 6 días. 


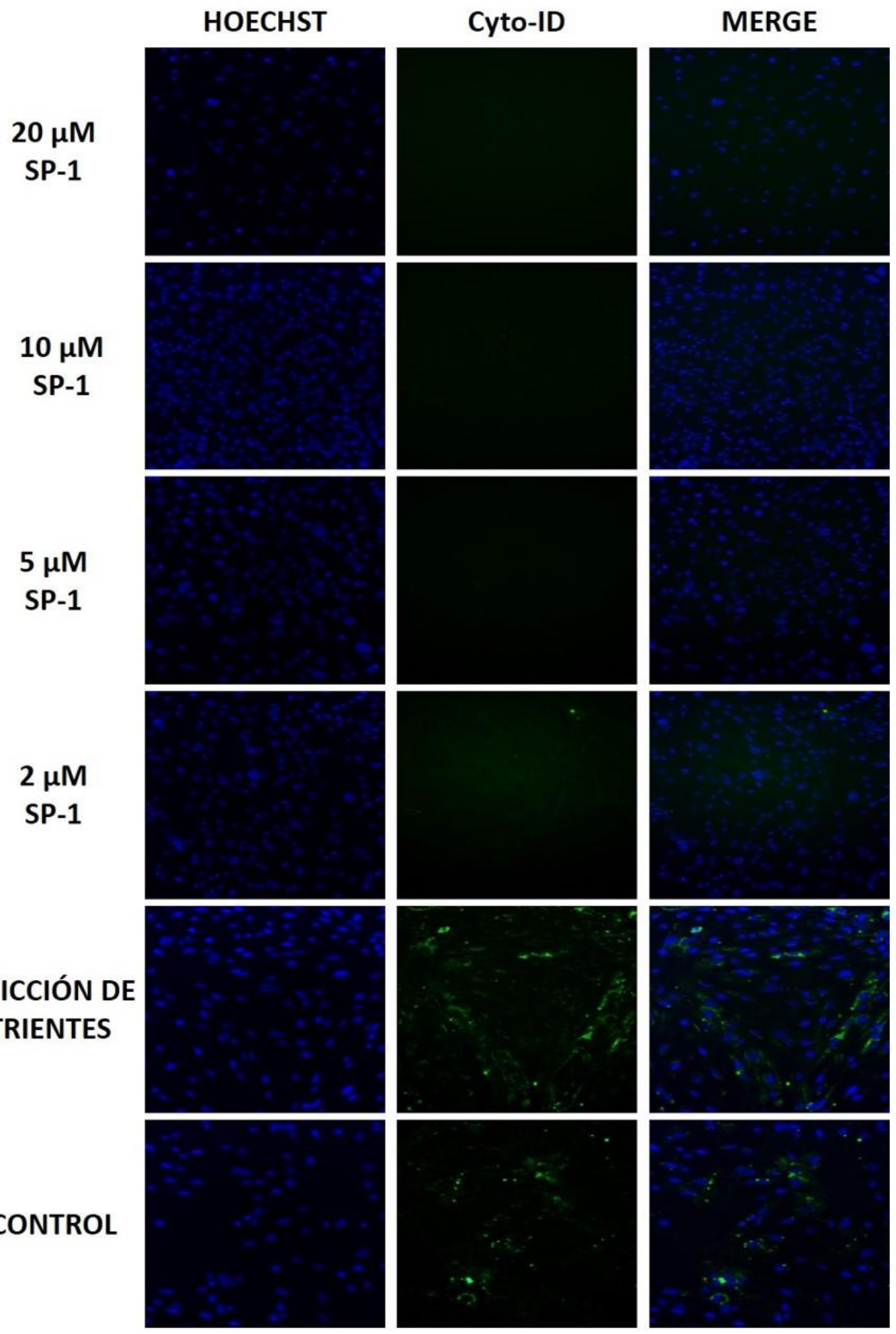

Figura 5. Fluorescencia de autofagosomas a 3 días. En la figura se muestra la formación de autofagosomas detectado por medio del kit Cyto-ID (verde) y los núcleos de los astrocitos teñidos con Hoechst (azul) para cada concentración de SP-1 utilizada. Se muestran imágenes representativas de cada experimento. 


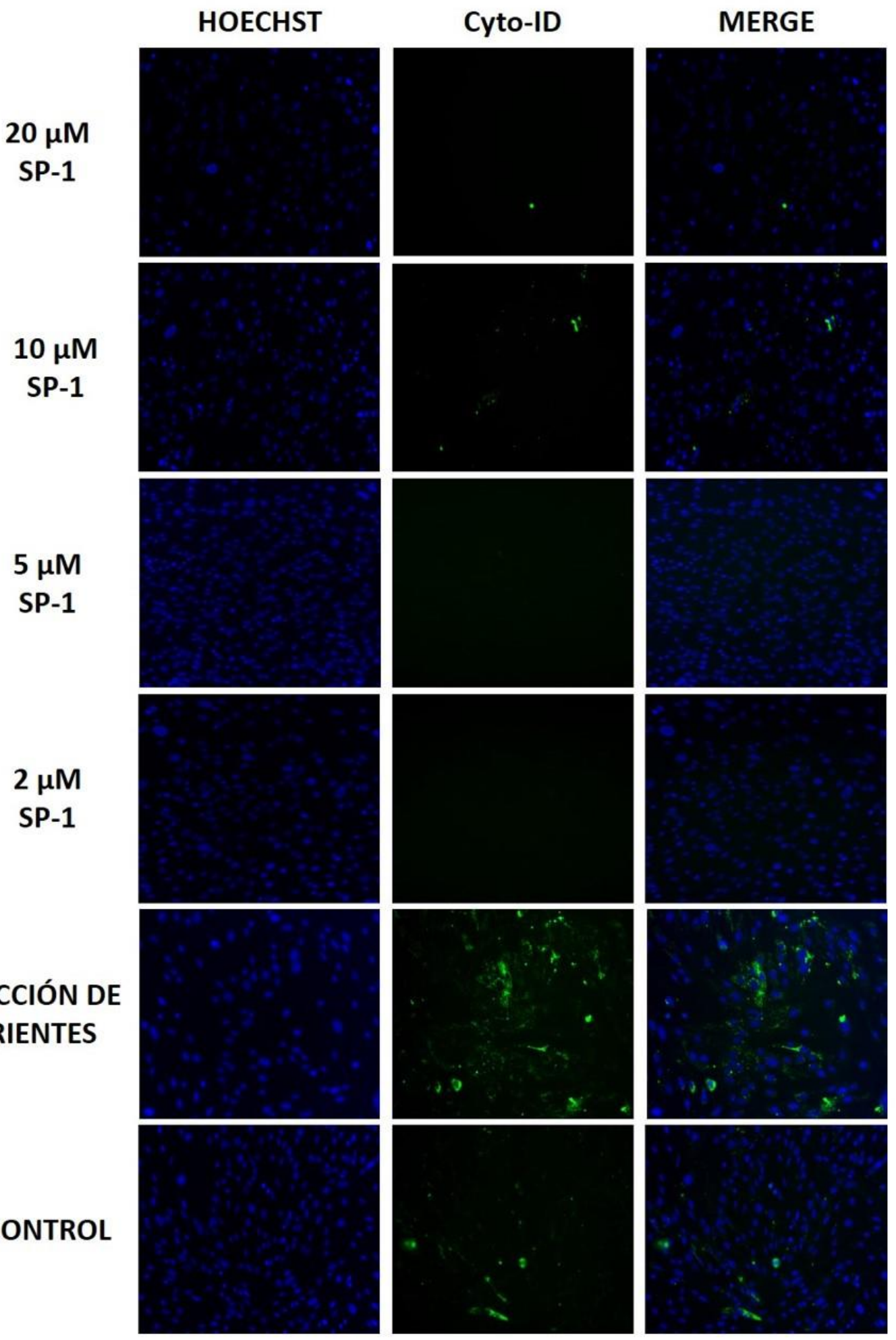

Figura 6. Fluorescencias de autofagosomas a 6 días. En la figura se muestra la formación de autofagosomas detectado por medio del kit Cyto-ID (verde) y los núcleos de los astrocitos teñidos con Hoechst (azul) para cada concentración de SP-1 utilizada. Se muestran imágenes representativas de cada experimento. 


\subsection{Marcadores clásicos de senescencia}

La inhibición de la proliferación que se muestra en la gráfica de la Figura 3 de los astrocitos tratados con SP-1 mostraban un comportamiento parecido a las gráficas de senescencia inducida por estrés reportadas en el laboratorio para fibroblastos primarios de pulmón de ratón (Lopez-Diazguerrero et al., 2006; Triana-Martinez et al., 2014; Maciel-Baron et al., 2016) se decidió emplear las concentraciones de 5 y 10 $\mu \mathrm{M}$ de SP-1, ya que la concentración de $20 \mu \mathrm{M}$ generó cambios morfológicos en las células con aparente daño.

\subsubsection{SA B-gal}

Una de las características de las células senescentes es el incremento en la actividad de la enzima ß-galactosidasa lisosomal, por esta razón dicho ensayo es considerado un marcador clásico para determinar la senescencia celular (Dimri et al., 1995; Rodier \& Campisi, 2011). De las imágenes obtenidas al realizar dicho ensayo se puede observar en la Figura 7, que a los 3 días de tratamiento con SP-1 no hay astrocitos teñidos positivamente para la actividad de ß-galactosidasa a ninguna concentración, y que únicamente fueron positivas las células usadas como control empleando $\mathrm{H}_{2} \mathrm{O}_{2}$ para inducir SIPS. Sin embargo, en la Figura 8 se observa que a los 6 días de tratamiento se observa un gran número de células positivas al ensayo. 


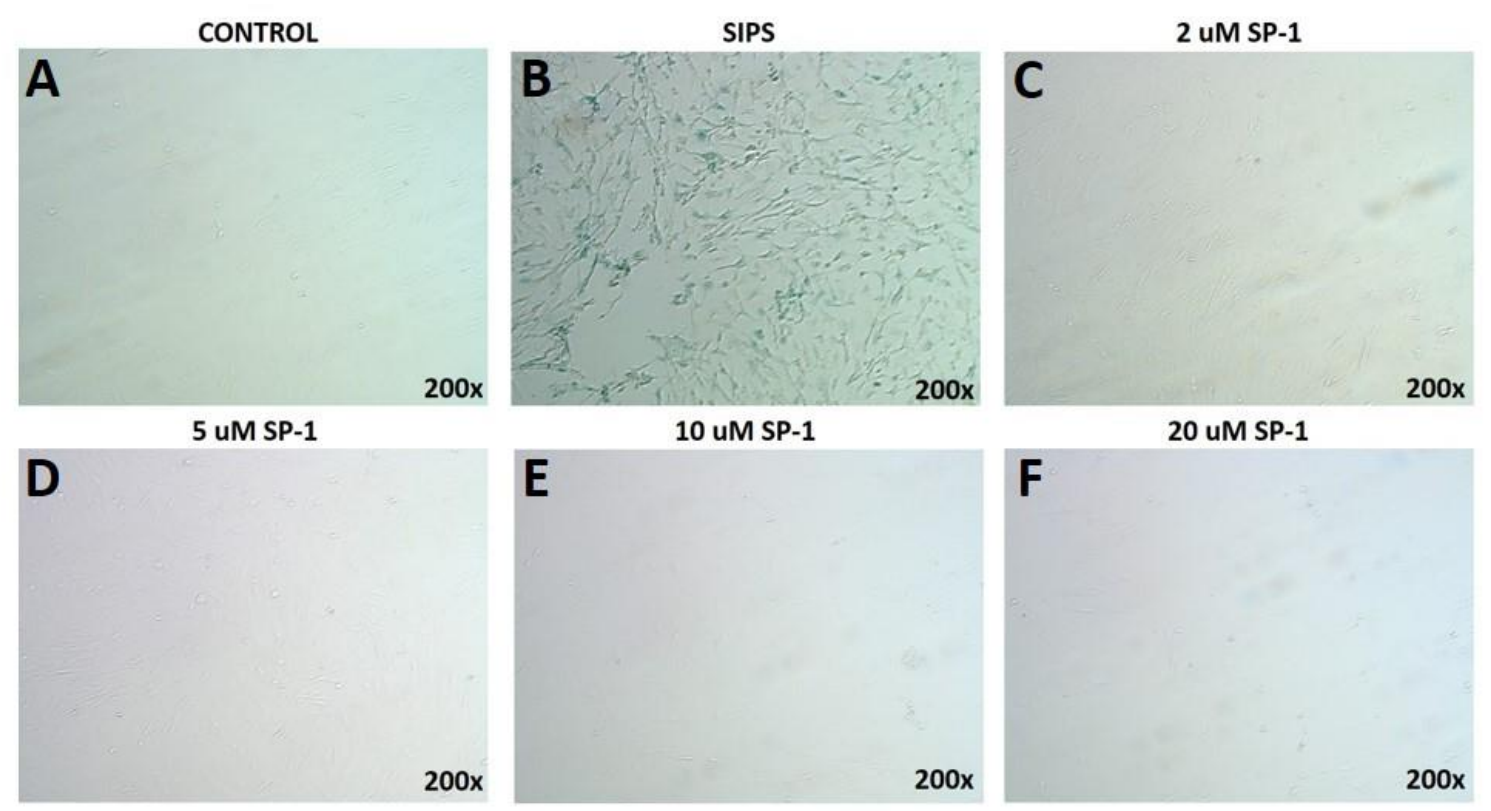

Figura 7. Ensayo SA ß-gal a 3 días. Imágenes representativas del ensayo SA ß-gal a tres dias del control (A), SIPS como control positivo $(B)$ y para los tratamientos con SP1 de las concentraciones $2 \mu \mathrm{M}(\mathrm{C}), 5 \mu \mathrm{M}(\mathrm{D}), 10 \mu \mathrm{M}(\mathrm{E})$ y $20 \mu \mathrm{M}(\mathrm{F})$.
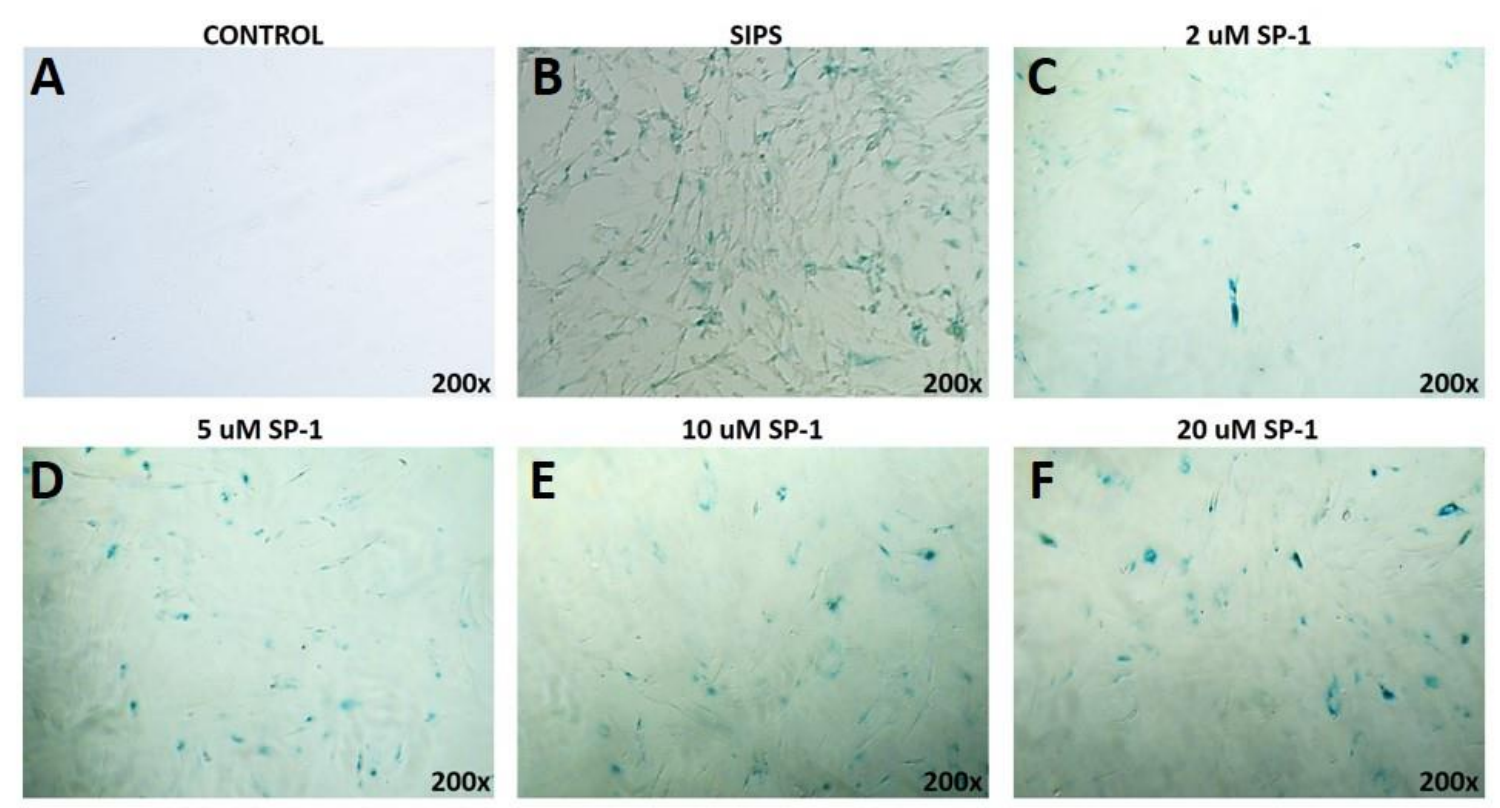

Figura 8. Ensayo SA ß-gal a 6 días. Imágenes representativas del ensayo SA ß-gal a tres días del control (A), SIPS como control positivo $(B)$ y para los tratamientos con SP1 de las concentraciones $2 \mu \mathrm{M}(\mathrm{C}), 5 \mu \mathrm{M}(\mathrm{D}), 10 \mu \mathrm{M}(\mathrm{E})$ y $20 \mu \mathrm{M}(\mathrm{F})$. 
Para corroborar el resultado se procedió a graficar el número de células positivas a SA B-gal y el resultado se muestra en la gráfica de la Figura 9, donde, se observa que los tratamientos a 3 días no generan un porcentaje de células senescentes diferente al control, mientras que a los 6 días si se observan diferencias significativas. El porcentaje de células senescentes de las concentraciones 5 y $10 \mu \mathrm{M}$ de SP-1 (mayor a 70\%) cae dentro de los criterios considerados para afirmar que la inhibición de la autofagia mediada por el SP-1 induce senescencia en los astrocitos de cultivo primario a los 6 días de exposición.

\section{SA ß-gal}

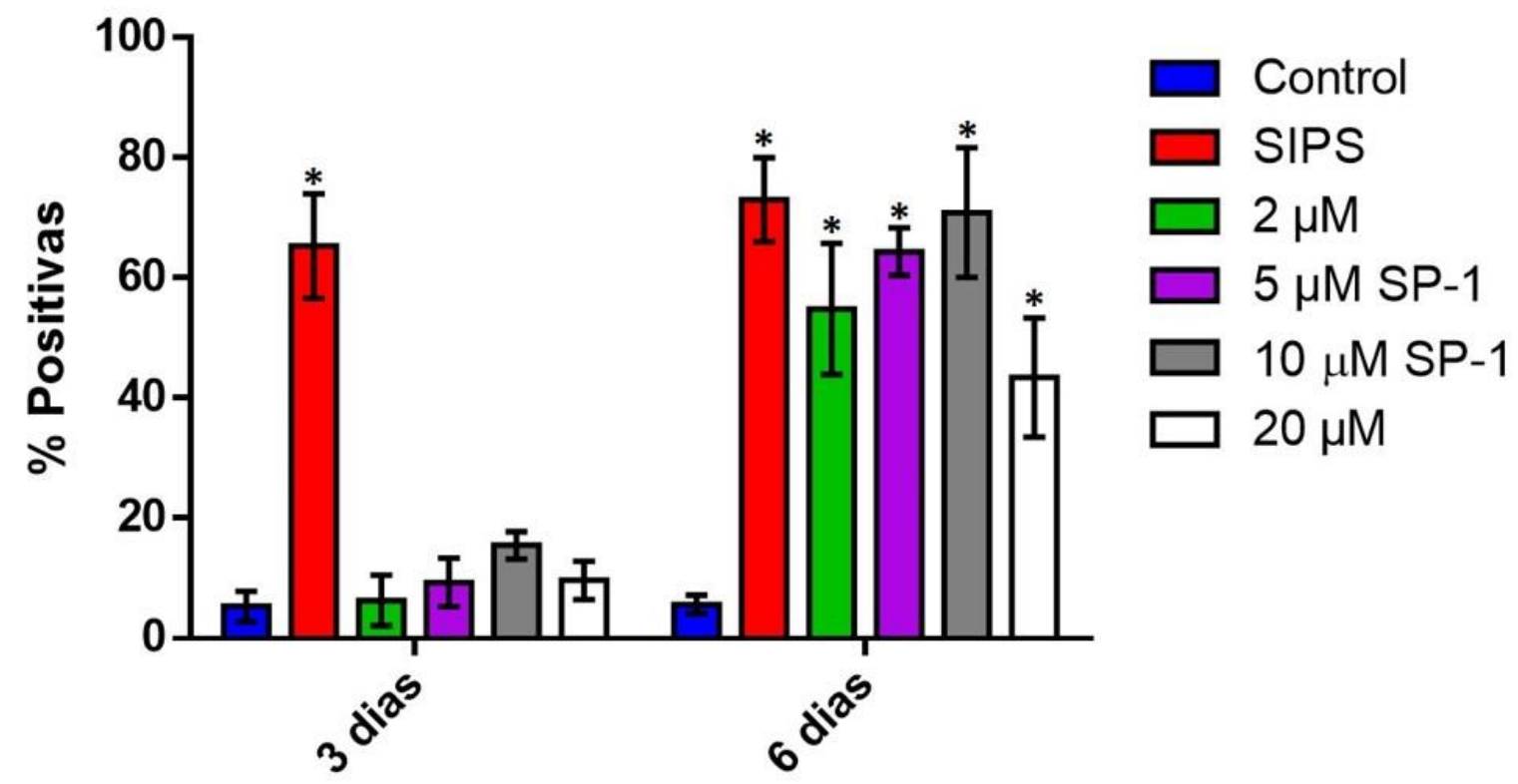

Figura 9. Gráfica de porcentaje de células positivas al ensayo SA B-gal. En la gráfica se muestra el porcentaje de células positivas al ensayo a 3 y 6 días para todos los grupos experimentales. Se realizaron 3 experimentos independientes por duplicado. ${ }^{*} p<0.05$ comparado con el control del día correspondiente. 


\subsubsection{Inmunofluorescencia de p16 y ß-galactosidasa.}

Para corroborar la inducción de senescencia, se analizó por inmunofluorescencia la presencia y localización del inhibidor del ciclo celular p16 (en el núcleo) y la proteína B-galactosidasa (en el citosol) en los astrocitos tratados con SP-1.

La Figura 10 muestra que los niveles de p16 y ß-galactosidasa los astrocitos tratados con SP-1 a 3 días no muestran un incremento con respecto al control.

Mientras que en la inmunofluorescencia de los astrocitos después de 6 días de tratamiento, se observa que hay un incremento en los niveles de p16, sin embargo, los niveles de B-galactosidasa se mantienen sin cambios respecto al control a pesar de mostrar un incremento en su actividad descrita en el ensayo de SA B-gal de la sección anterior. 


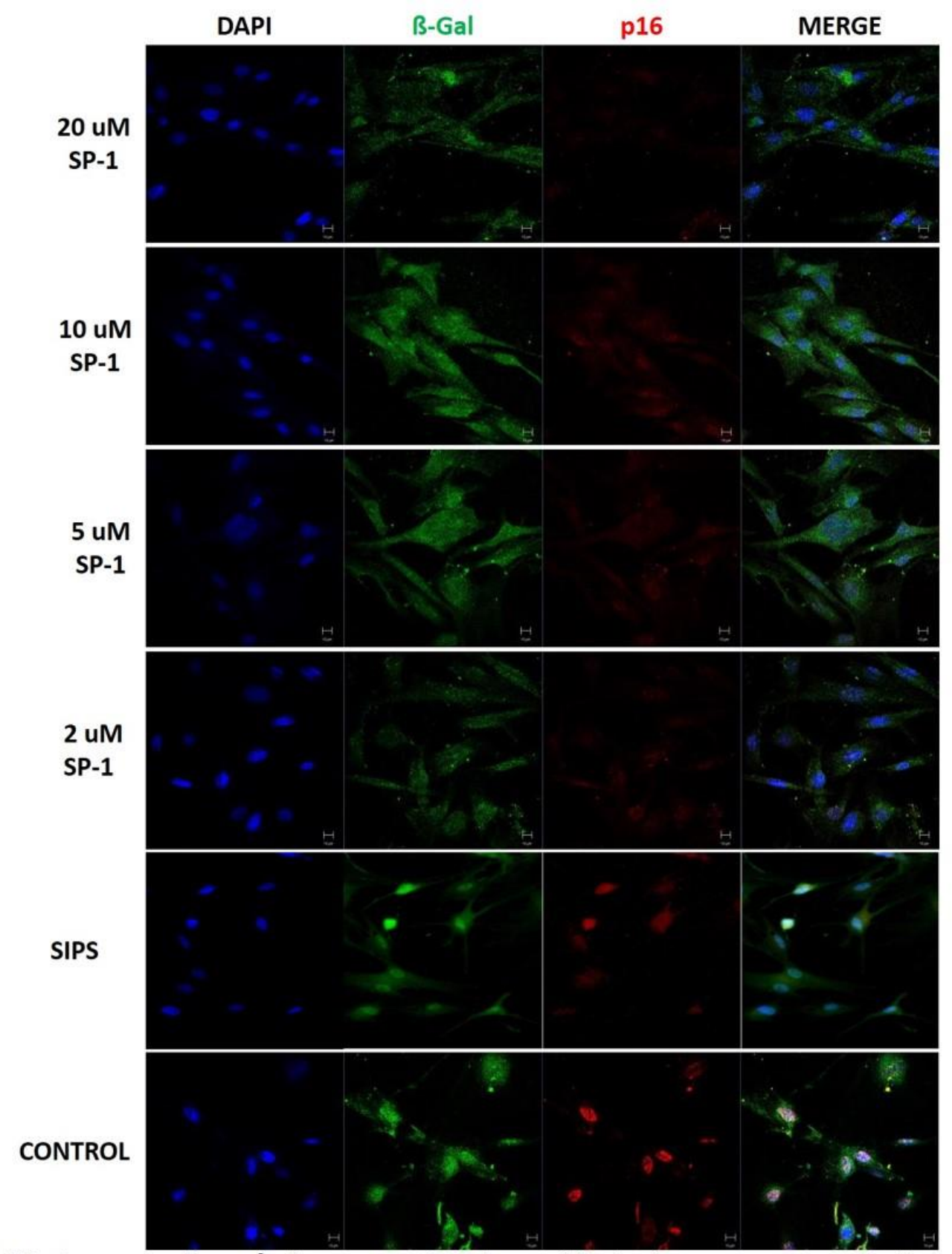

Figura 10. Inmunocitoquímica para ß-gal y p16. Imágenes representativas de la inmunocitoquímica de marcadores de senescencia ß-gal (verde) y p16 (rojo), los núcleos fueron marcados con DAPI (azul). 


\subsubsection{Western-Blot de los inhibidores del ciclo celular}

Además de p16, existen otros supresores de ciclo involucrados en la detención permanente de la proliferación celular durante la senescencia, tal es el caso de p21 y p27. En la Figura 12 se observa el contenido total de las proteínas antes mencionadas a 3 y 6 días de tratamiento con SP-1 a concentraciones de 5 y $10 \mu \mathrm{M}$.

Para la proteína p16, las densitometrías muestran que el aumento solo es significativo en el tratamiento de $10 \mu \mathrm{M}$ de SP-1 a los 6 días con respecto al control.

Para el caso de p21, de forma interesante, todos los tratamientos de SP-1 muestran un decremento estadísticamente significativo con respecto al control, que mantiene niveles similares a los del control positivo de senescencia, sugiriendo que esta molécula no participa en la inhibición del ciclo celular por autofagia en astrocitos.

De forma similar p27, muestra una disminución en sus niveles de proteína significativamente diferentes en los tratamientos de SP-1 de $5 \mu \mathrm{M}$ a 3 y 6 días, mientras que para $10 \mu \mathrm{M}$ solo a los 6 días.

En cuanto a p53, se observa que sus niveles disminuyen significativamente respecto al control a los 3 y 6 días de las 2 concentraciones que se utilizaron, corroborando que SP-1 induce la degradación de p53 (Liu et al., 2011) 


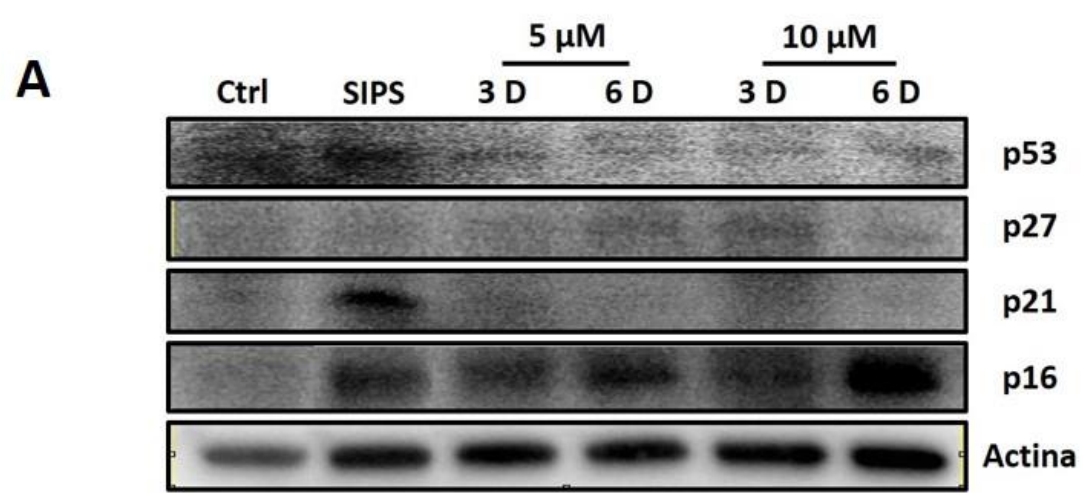

B

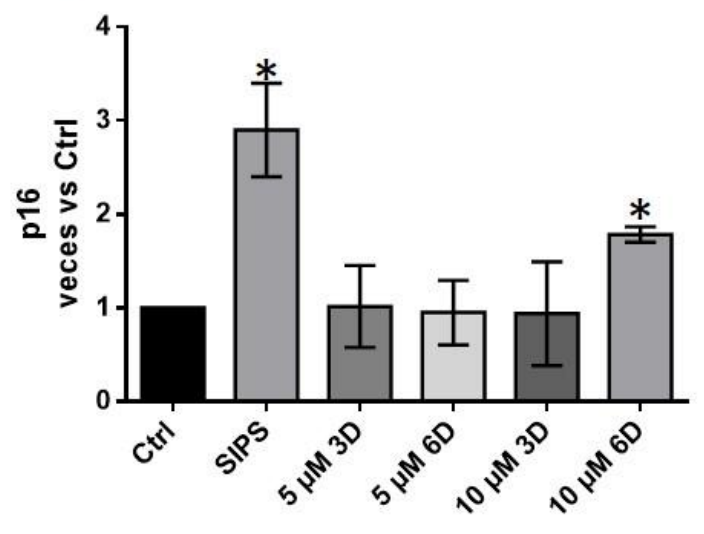

D

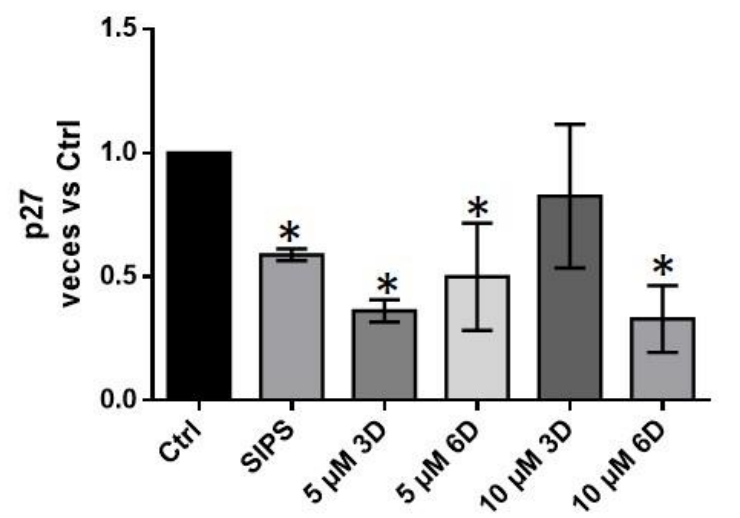

C

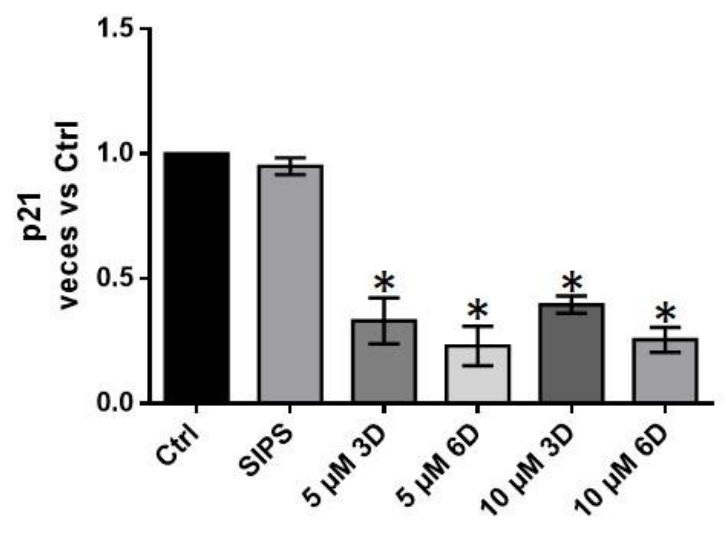

$\mathbf{F}$

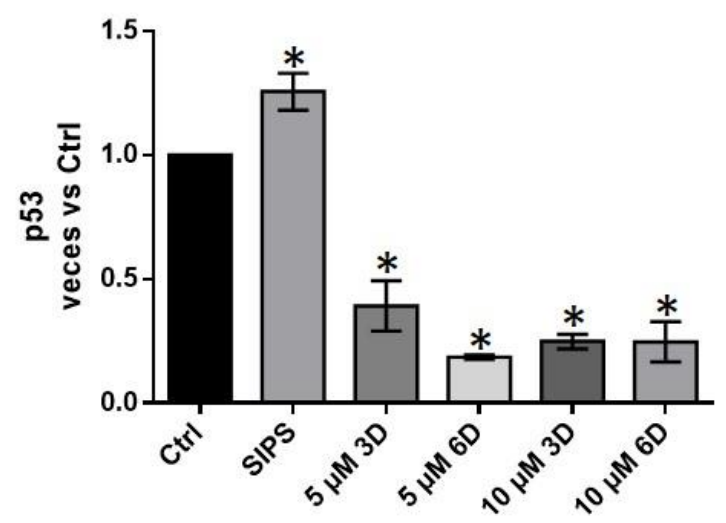

Figura 12. Western Blot para p16, p21, p27 y p53. Membrana representativa de los niveles de proteína de los supresores de ciclo (A) y densitometrías de p16 (B), p21 (C), p27 (D) y p53 (F).

${ }^{*} p<0.05$ comparado con el control. 


\section{Discusión}

La pérdida de proteostasis se considera como un factor desencadenante de la senescencia (Torres et al., 2006; Maciel-Baron et al., 2016). Sin embargo, el rol de la autofagia como inductor de senescencia ha resultado controversial en diversos estudios. Algunas investigaciones han encontrado que una actividad elevada de la autofagia permite que las células evadan la entrada a la senescencia (Demidenko et al., 2009; Pospelova et al., 2012; Pospelova et al., 2013; Garcia-Prat et al., 2016) y que estudios como el de Kang y colaboradores en 2011 sugieren que su inhibición conduce prematuramente a este estado (Kang et al., 2011). Sin embargo, otros trabajos sugieren que una actividad alta de la autofagia también puede conducir a las células a un estado senescente (Shimi et al., 2011; Dou et al., 2015; Dou et al., 2016). Así mismo, se ha reportado que la autofagia incrementa al inducirse la senescencia, pero que si se inhibe no se induce la senescencia (Young et al., 2009).

Por todo lo anterior, el papel de la autofagia en la senescencia no ha quedado claro a lo largo de estos años. Es notorio que las diferencias entre los resultados obtenidos pueden deberse al tipo y origen de las células que fueron utilizadas en dichos trabajos (fibroblastos de humano, ratón y líneas celulares de cáncer) y con ello podría explicarse esta variación de los resultados, además de que se utilizó un mecanismo de inhibición distinto en cada uno de ellos.

En este trabajo se evaluó la inducción de senescencia por inhibición de la autofagia en astrocitos de cultivo primario de rata, empleando para ello el químico SP-1 que 
funge como un inhibidor de la autofagia. Se evaluaron varias concentraciones de SP1 que van desde 2, 5, 10 hasta $20 \mu \mathrm{M}$ durante 3 y 6 días del tratamiento.

En primera instancia se realizó un cultivo primario de astrocitos el cual fue validado con la expresión de GFAP, una proteína de filamentos intermedios característica de los astrocitos, que se utiliza ampliamente para identificarlos (Bitto et al., 2010; Bhat et al., 2012; Alarcon-Aguilar et al., 2014).

En cuanto a la proliferación celular, el SP-1 tuvo un efecto notorio, sobre todo a concentraciones de 5,10 y $20 \mu \mathrm{M}$ como se observa en la figura 3, la cual muestra la consistencia de los datos bajo dos técnicas distintas.

La concentración de $20 \mu \mathrm{M}$ de SP-1 fue letal, ya que induce la muerte de los astrocitos y se observaron niveles de carbonilación de proteína muy elevados después de 6 días de tratamiento, por lo que se decidió no emplearla, sin embargo, aún queda por demostrar si dicho efecto es generado por la inhibición de la autofagia o bien si la molécula por si misma es citotóxica.

Se ha visto que la inhibición de la autofagia puede generar muerte mediante mecanismos relacionados a la acumulación de daño oxidante, es decir, al no poder degradar proteínas alteradas, el daño persiste y se expande a otras biomoléculas como el DNA, donde la respuesta de la célula al no poder contender al estrés, resulta en la inducción de la apoptosis (Wu y Cederbaum, 2013). Por otro lado, la autofagia también se encarga de eliminar organelos disfuncionales, como por ejemplo las mitocondrias en el proceso conocido como mitofagia, si ésta falla, las mitocondrias 
alteradas también generarán ERO perpetuando el daño celular (Bingol y Sheng, 2016; Kiriyama y Nochi, 2015; Springer y Macleod, 2016).

Después de tratar a los astrocitos con el inhibidor de la autofagia se evaluaron diferentes marcadores de senescencia como la presencia de p16 y B-gal por inmunofluorescencia, los niveles de inhibidores de ciclo celular por western blot y el ensayo SA B-gal. Todos los experimentos confirmaron que la inhibición de la autofagia induce la senescencia después de 6 días con el tratamiento de SP-1 a 5 y $10 \mu \mathrm{M}$.

En el caso de la inmunofluorescencia donde no se incrementan los niveles de proteína ß-galactosidasa a pesar de que en los ensayos de SA B-gal resultaron positivas, no quiere decir que la actividad de la enzima no pueda ser superior en las células senescentes. Se ha reportado que el incremento en la actividad de la enzima B-galactosidasa no siempre correlaciona con sus niveles de proteína (Capparelli et al., 2012), aunque para validarlo se necesitaría realizar una cinética enzimática para B-galactosidasa en cultivos con astrocitos senescentes.

En cuanto a los resultados obtenidos por los inhibidores del ciclo celular, resultó interesante encontrar que ni p21, ni p27 aumentaron y más bien disminuyeron de forma significativa con respecto al control. La baja significativa en los niveles de proteína de p21 puede deberse a que se ha reportado, SP-1 induce la degradación p53 ya que inhibe a la desubiquitinasa USP-10 encargada de retirar las ubiquitinas a esta proteína, favoreciendo de este modo que se degrade vía proteosoma. 
Los niveles de proteína a la baja correspondientes a p27 podrían estar ligados a que se ha sugerido que este inhibidor de ciclo refuerza el estímulo de la senescencia en tiempos más largos y es probable que 6 días no sean suficiente tiempo en cultivo para poder observar un incremento en éste (Triana-Martínez et al., 2014).

Por otro lado, p16 muestra un incremento significativo en su expresión relativa con respecto al control a los 6 días del tratamiento con SP-1 a la concentración de $10 \mu \mathrm{M}$, coincidiendo con la entrada a senescencia.

Interesantemente, estos resultados sugieren que la entrada a senescencia es independiente de p53, por lo que quedaría por demostrar que la entrada a senescencia es causada por la inhibición de la autofagia mediante mecanismos que involucran la acumulación de daño oxidante. Este daño fue evidente en la prueba de carbonilación de proteínas donde se observó niveles significativamente superiores a los del control y estadísticamente iguales a los del control positivo de SIPS. A pesar de este resultado es pertinente mantener como perspectiva dilucidar si el daño oxidante se limita a la oxidación de proteínas o se encuentren mitocondrias dañadas con funcionamiento comprometido, daño en DNA o lipoperoxidación, desencadenando la senescencia celular como ha sido reportado para otros modelos (Iwasa, 2003; Muller, 2009; Wu y Cederbaum, 2013).

Por otro lado, se ha reportado que p38 se activa durante la senescencia e incluso es considerado como un marcador de células senescentes (Iwasa et al., 2003; Harada, 2014; Alimbetov et al., 2016). p38 podría actuar de dos maneras, la primera tiene que ver con la regulación de la autofagia, puesto que se ha demostrado que p38 participa 
tanto en la inhibición como en la inducción de este mecanismo (Webber y Tooze, 2010; Keil et al., 2013; Pan et al., 2015; Wei et al., 2015; Wang y Ren, 2016). Esta cinasa puede ejercer la regulación de la autofagia en varios puntos, por ejemplo, puede fosforilar a mTOR, activándola y de esta forma inhibir la autofagia ya que esta proteína fosforila al complejo Ulk-1 impidiendo que se inicie la formación del fagóforo (Pan et al., 2015; Wang y Ren, 2016). Otro mecanismo de regulación de p38 es que puede fosforilar a Atg9 y Atg5 para la inhibición de la autofagia (Webber y Tooze, 2010; Keil et al., 2013). Por otro lado, también puede fosforilar directamente a Beclin1 favoreciendo de este modo la autofagia (Wei et al., 2015), sin embargo, puesto que SP-1 se encuentra inhibiendo la autofagia vía la degradación de Beclin-1 (Liu et al., 2011) y no se observa formación de autofagosomas en los astrocitos tratados, se piensa que p38 podría estar favoreciendo también la inhibición de la autofagia una vez que las células entran en senescencia.

La segunda función de p38 tiene que ver con la activación de p16, el único inhibidor de ciclo que se incrementa de los que fueron evaluados aunque aún no se sabe con claridad el mecanismo por el cual regula los niveles de esta proteína, pero que además puede contribuir a la hiperfosforilación de pRB como un mecanismo alterno para el control de la proliferación de las células (Iwasa et al., 2003; Bulavin y Fornace, 2004; Bulavin et al., 2004; Papaconstantinou et al., 2015). Con lo anterior podríamos hipotetizar que p38 participa entonces en el mantenimiento del estímulo de senescencia, por un lado manteniendo la inhibición de la autofagia y por otro favoreciendo la detención del ciclo celular mediante la activación de p16. 
Respecto al ensayo de SA B-gal, con las concentraciones de 5 y $10 \mu \mathrm{M}$ se alcanzaron porcentajes mayores a $70 \%$ de células senescentes a los 6 días de tratamiento. No así para la concentración de $2 \mu \mathrm{M}$ que, aunque dió positivo para el ensayo de ß-galactosidasa, no alcanzó un porcentaje alto de células positivas para ser considerado como senescencia prematura inducida con respecto a lo reportado en la literatura. Además, quedan dudas al respecto dado que su curva de proliferación no mostró diferencias significativas respecto al control, es decir, no se detuvo su ciclo celular como es característico de este fenómeno.

Resulta interesante resaltar que a los 6 días de tratamiento los astrocitos ya eran senescentes a las concentraciones de 5 y $10 \mu \mathrm{M}$ de SP-1 por lo que no existen indicios de que la autofagia sea necesaria para la transición a este estado celular (al menos en este modelo) como lo reportó Young en 2009. Curiosamente y aunque no se reporta en el presente trabajo, el mantenimiento del estímulo con SP-1 después de los 7 u 8 días generó que los platos de cultivo quedaran completamente vacíos, es decir, las células se despegaron de la base de la placa, lo que podría sustentar el hecho de que la autofagia si podría ser necesaria para el mantenimiento del fenotipo senescente (Young et al., 2009).

Cabe resaltar que de la misma forma sería muy importante evaluar el SASP de este modelo de inducción de senescencia en astrocitos para saber si es distinto con respecto al mecanismo de inducción de senescencia como ya fue reportado para fibroblastos de pulmón de ratón en nuestro grupo de trabajo (Maciel-Baron et al., 
2016), esto debido a que la autofagia es un proceso fundamental en la producción de las moléculas secretadas en el SASP (Young et al., 2009).

Finalmente, y con base en los resultados obtenidos se propone que la inhibición de la autofagia permite alcanzar el estado senescente. Esto puede estar relacionado con la acumulación de daño oxidante generado por la inhibición de este mecanismo mediante el uso de SP-1, que induce la degradación vía proteosoma de Beclin-1 y p53.

Las ERO generadas favorecerían entonces el daño a biomoléculas, como proteínas y DNA, desencadenando de esta forma la senescencia celular mediante un mecanismo independiente de p53. Las ERO además pueden inducir la actividad de la cinasa p38, una proteína que se encuentra en grandes cantidades cuando se alcanza la senescencia y se propone en este modelo como un participante importante en el mantenimiento del estímulo de inhibición de la autofagia por mecanismos discutidos anteriormente y del refuerzo de la senescencia mediante la inducción de p16, un supresor de ciclo celular y la regulación de la secreción del SASP.

El entendimiento de la autofagia como un mecanismo de inducción de senescencia en este modelo de astrocitos primarios de rata puede representar un punto de partida para poder encontrar una forma de aminorar el daño generado por los astrocitos senescentes presentes en patologías prevalentes en adultos mayores de carácter neurodegenerativo como el Alzheimer, permitiendo de esta forma mejorar la calidad de vida de las personas que padecen estas enfermedades. 


\section{Conclusiones}

- SP-1 inhibe la autofagia en astrocitos de rata de cultivo primario a todas las concentraciones evaluadas a 3 y 6 días.

- SP-1 ralentiza la proliferación de los astrocitos primarios de rata a concentraciones de 5,10 y $20 \mu \mathrm{M}$.

- Se induce senescencia en astrocitos de cultivo primario de rata por inhibición de la autofagia a concentraciones de 5 y $10 \mu \mathrm{M}$ de SP-1 evaluado a 6 días.

\section{Perspectivas}

- Validar el efecto de otros inhibidores de la autofagia como bafilomicina o 3metil adenina y verificar si se tiene el mismo efecto sobre la inducción de senescencia en los astrocitos primarios de rata.

- Analizar el papel de p38 sobre la regulación de la autofagia en este modelo de inducción de senescencia.

- Verificar la vía de señalización del mecanismo de inducción de senescencia para SP-1, ya que se vio que es un mecanismo independiente de p53 y si es posible, compararlo con los otros inhibidores.

- Estudiar la composición del SASP de este mecanismo de inducción de senescencia y compararlo con otros modelos de senescencia en astrocitos. 


\section{Bibliografía}

Alarcon-Aguilar, A., Luna-Lopez, A., Ventura-Gallegos, J. L., Lazzarini, R., GalvanArzate, S., Gonzalez-Puertos, V. Y., . . . Konigsberg, M. (2014). Primary cultured astrocytes from old rats are capable to activate the Nrf2 response against MPP+ toxicity after tBHQ pretreatment. Neurobiol Aging, 35(8), 19011912. doi:10.1016/j.neurobiolaging.2014.01.143

Alimbetov, D., Davis, T., Brook, A. J., Cox, L. S., Faragher, R. G., Nurgozhin, T., . . . Kipling, D. (2016). Suppression of the senescence-associated secretory phenotype (SASP) in human fibroblasts using small molecule inhibitors of p38 MAP kinase and MK2. Biogerontology, 17(2), 305-315. doi:10.1007/s10522015-9610-z

Alvers, A. L., Wood, M. S., Hu, D., Kaywell, A. C., Dunn, W. A., Jr., \& Aris, J. P. (2009). Autophagy is required for extension of yeast chronological life span by rapamycin. Autophagy, 5(6), 847-849.

Bhat, R., Crowe, E. P., Bitto, A., Moh, M., Katsetos, C. D., Garcia, F. U., . . Torres, C. (2012). Astrocyte senescence as a component of Alzheimer's disease. PLoS One, 7(9), e45069. doi:10.1371/journal.pone.0045069

Bigagli, E., Luceri, C., Scartabelli, T., Dolara, P., Casamenti, F., Pellegrini-Giampietro, D. E., \& Giovannelli, L. (2015). Long-term Neuroglial Cocultures as a Brain Aging Model: Hallmarks of Senescence, MicroRNA Expression Profiles, and Comparison With In Vivo Models. J Gerontol A Biol Sci Med Sci. doi:10.1093/gerona/glu231

Bingol, B., \& Sheng, M. (2016). Mechanisms of mitophagy: PINK1, Parkin, USP30 and beyond. Free Radic Biol Med. doi:10.1016/j.freeradbiomed.2016.04.015

Bitto, A., Ito, T. K., Pineda, V. V., LeTexier, N. J., Huang, H. Z., Sutlief, E., . . . Kaeberlein, M. (2016). Transient rapamycin treatment can increase lifespan and healthspan in middle-aged mice. Elife, 5. doi:10.7554/eLife.16351

Bitto, A., Sell, C., Crowe, E., Lorenzini, A., Malaguti, M., Hrelia, S., \& Torres, C. (2010). Stress-induced senescence in human and rodent astrocytes. Exp Cell Res, 316(17), 2961-2968. doi:10.1016/j.yexcr.2010.06.021

Blagosklonny, M. V. (2013). Hypoxia, MTOR and autophagy: converging on senescence or quiescence. Autophagy, 9(2), 260-262. doi:10.4161/auto.22783

Braselmann, E., Chaney, J. L., \& Clark, P. L. (2013). Folding the proteome. Trends Biochem Sci, 38(7), 337-344. doi:10.1016/j.tibs.2013.05.001

Bulavin, D. V., \& Fornace, A. J., Jr. (2004). p38 MAP kinase's emerging role as a tumor suppressor. Adv Cancer Res, 92, 95-118. doi:10.1016/S0065230X(04)92005-2

Bulavin, D. V., Phillips, C., Nannenga, B., Timofeev, O., Donehower, L. A., Anderson, C. W., . . Fornace, A. J., Jr. (2004). Inactivation of the Wip1 phosphatase inhibits mammary tumorigenesis through p38 MAPK-mediated activation of the p16(Ink4a)-p19(Arf) pathway. Nat Genet, 36(4), 343-350. doi:10.1038/ng1317

Campisi, J., \& Robert, L. (2014). Cell senescence: role in aging and age-related diseases. Interdiscip Top Gerontol, 39, 45-61. doi:10.1159/000358899 
Capparelli, C., Chiavarina, B., Whitaker-Menezes, D., Pestell, T. G., Pestell, R. G., Hulit, J., . . . Lisanti, M. P. (2012). CDK inhibitors (p16/p19/p21) induce senescence and autophagy in cancer-associated fibroblasts, "fueling" tumor growth via paracrine interactions, without an increase in neo-angiogenesis. Cell Cycle, 11(19), 3599-3610. doi:10.4161/cc.21884

Castro, S. (2012). La autofagia en el proceso del envejecimiento Aspectos moleculares del envejecimiento (1 ed., pp. 101-110): Lopez-Muñoz E, TorresCarrillo.

Cuervo, A. M. (2010). The plasma membrane brings autophagosomes to life. Nat Cell Biol, 12(8), 735-737. doi:10.1038/ncb0810-735

Cuervo, A. M., \& Macian, F. (2014). Autophagy and the immune function in aging. Curr Opin Immunol, 29, 97-104. doi:10.1016/j.coi.2014.05.006

Cuervo, A. M., \& Wong, E. (2014). Chaperone-mediated autophagy: roles in disease and aging. Cell Res, 24(1), 92-104. doi:10.1038/cr.2013.153

Chen, Y., \& Klionsky, D. J. (2011). The regulation of autophagy - unanswered questions. J Cell Sci, 124(Pt 2), 161-170. doi:10.1242/jcs.064576

Chinta, S. J., Woods, G., Rane, A., Demaria, M., Campisi, J., \& Andersen, J. K. (2014). Cellular senescence and the aging brain. Exp Gerontol. doi:10.1016/j.exger.2014.09.018

Davalos, A. R., Coppe, J. P., Campisi, J., \& Desprez, P. Y. (2010). Senescent cells as a source of inflammatory factors for tumor progression. Cancer Metastasis Rev, 29(2), 273-283. doi:10.1007/s10555-010-9220-9

Demaria, M., Ohtani, N., Youssef, S. A., Rodier, F., Toussaint, W., Mitchell, J. R., . . . Campisi, J. (2014). An essential role for senescent cells in optimal wound healing through secretion of PDGF-AA. Dev Cell, 31(6), 722-733. doi:10.1016/j.devcel.2014.11.012

Demidenko, Z. N., Zubova, S. G., Bukreeva, E. I., Pospelov, V. A., Pospelova, T. V., \& Blagosklonny, M. V. (2009). Rapamycin decelerates cellular senescence. Cell Cycle, 8(12), 1888-1895. doi:10.4161/cc.8.12.8606

Dimri, G. P., Lee, X., Basile, G., Acosta, M., Scott, G., Roskelley, C., . . et al. (1995). A biomarker that identifies senescent human cells in culture and in aging skin in vivo. Proc Natl Acad Sci U S A, 92(20), 9363-9367.

Dou, Z., Ivanov, A., Adams, P. D., \& Berger, S. L. (2016). Mammalian autophagy degrades nuclear constituents in response to tumorigenic stress. Autophagy, 12(8), 1416-1417. doi:10.1080/15548627.2015.1127465

Dou, Z., Xu, C., Donahue, G., Shimi, T., Pan, J. A., Zhu, J., . . Berger, S. L. (2015). Autophagy mediates degradation of nuclear lamina. Nature, 527(7576), 105109. doi: $10.1038 /$ nature 15548

Finch, C. E., \& Tanzi, R. E. (1997). Genetics of aging. Science, 278(5337), 407-411.

Freund, A., Orjalo, A. V., Desprez, P. Y., \& Campisi, J. (2010). Inflammatory networks during cellular senescence: causes and consequences. Trends Mol Med, 16(5), 238-246. doi:10.1016/j.molmed.2010.03.003

Garcia-Prat, L., Martinez-Vicente, M., Perdiguero, E., Ortet, L., Rodriguez-Ubreva, J., Rebollo, E., . . . Munoz-Canoves, P. (2016). Autophagy maintains stemness by preventing senescence. Nature, 529(7584), 37-42. doi:10.1038/nature16187 
Harada, G., Neng, Q., Fujiki, T., \& Katakura, Y. (2014). Molecular mechanisms for the p38-induced cellular senescence in normal human fibroblast. $J$ Biochem, 156(5), 283-290. doi:10.1093/jb/mvu040

Harman, D. (1956). Aging: a theory based on free radical and radiation chemistry. $J$ Gerontol, 11(3), 298-300.

Hayflick, L. (1965). The Limited in Vitro Lifetime of Human Diploid Cell Strains. Exp Cell Res, 37, 614-636.

Hayflick, L., \& Moorhead, P. S. (1961). The serial cultivation of human diploid cell strains. Exp Cell Res, 25, 585-621.

Iwasa, H., Han, J., \& Ishikawa, F. (2003). Mitogen-activated protein kinase p38 defines the common senescence-signalling pathway. Genes Cells, 8(2), 131144.

Jones, D. P. (2015). Redox theory of aging. Redox Biology, 5, 71-79. doi:10.1016/j.redox.2015.03.004

Kang, H. T., Lee, K. B., Kim, S. Y., Choi, H. R., \& Park, S. C. (2011). Autophagy impairment induces premature senescence in primary human fibroblasts. PLoS One, 6(8), e23367. doi:10.1371/journal.pone.0023367

Keil, E., Hocker, R., Schuster, M., Essmann, F., Ueffing, N., Hoffman, B., . . Schmitz, I. (2013). Phosphorylation of Atg5 by the Gadd45beta-MEKK4-p38 pathway inhibits autophagy. Cell Death Differ, 20(2), 321-332. doi:10.1038/cdd.2012.129

Kennedy, B. K., Berger, S. L., Brunet, A., Campisi, J., Cuervo, A. M., Epel, E. S., . . . Sierra, F. (2014). Geroscience: linking aging to chronic disease. Cell, 159(4), 709-713. doi:10.1016/j.cell.2014.10.039

Kiriyama, Y., \& Nochi, H. (2015). The Function of Autophagy in Neurodegenerative Diseases. Int J Mol Sci, 16(11), 26797-26812. doi:10.3390/ijms161125990

Laberge, R. M., Zhou, L., Sarantos, M. R., Rodier, F., Freund, A., de Keizer, P. L., . . . Campisi, J. (2012). Glucocorticoids suppress selected components of the senescence-associated secretory phenotype. Aging Cell, 11(4), 569-578. doi:10.1111/j.1474-9726.2012.00818.x

Li, W. W., Li, J., \& Bao, J. K. (2012). Microautophagy: lesser-known self-eating. Cell Mol Life Sci, 69(7), 1125-1136. doi:10.1007/s00018-011-0865-5

Liu, J., Xia, H., Kim, M., Xu, L., Li, Y., Zhang, L., . . Yuan, J. (2011). Beclin1 controls the levels of p53 by regulating the deubiquitination activity of USP10 and USP13. Cell, 147(1), 223-234. doi:10.1016/j.cell.2011.08.037

Lopez-Diazguerrero, N. E., Lopez-Araiza, H., Conde-Perezprina, J. C., Bucio, L., Cardenas-Aguayo, M. C., Ventura, J. L., . . . Konigsberg, M. (2006). Bcl-2 protects against oxidative stress while inducing premature senescence. Free Radic Biol Med, 40(7), 1161-1169. doi:10.1016/j.freeradbiomed.2005.11.002

Lopez-Otin, C., Blasco, M. A., Partridge, L., Serrano, M., \& Kroemer, G. (2013). The hallmarks of aging. Cell, 153(6), 1194-1217. doi:10.1016/j.cell.2013.05.039

Maciel-Baron, L. A., Morales-Rosales, S. L., Aquino-Cruz, A. A., Triana-Martinez, F., Galvan-Arzate, S., Luna-Lopez, A., . . . Konigsberg, M. (2016). Senescence associated secretory phenotype profile from primary lung mice fibroblasts 
depends on the senescence induction stimuli. Age (Dordr), 38(1), 26. doi:10.1007/s11357-016-9886-1

Muller, M. (2009). Cellular senescence: molecular mechanisms, in vivo significance, and redox considerations. Antioxid Redox Signal, 11(1), 59-98. doi:10.1089/ars.2008.2104

Neff, F., Flores-Dominguez, D., Ryan, D. P., Horsch, M., Schroder, S., Adler, T., . . . Ehninger, D. (2013). Rapamycin extends murine lifespan but has limited effects on aging. J Clin Invest, 123(8), 3272-3291. doi:10.1172/JCl67674

Pan, S. T., Qin, Y., Zhou, Z. W., He, Z. X., Zhang, X., Yang, T., . . . Zhou, S. F. (2015). Plumbagin induces G2/M arrest, apoptosis, and autophagy via p38 MAPK- and PI3K/Akt/mTOR-mediated pathways in human tongue squamous cell carcinoma cells. Drug Des Devel Ther, 9, 1601-1626. doi:10.2147/DDDT.S76057

Papaconstantinou, J., Wang, C. Z., Zhang, M., Yang, S., Deford, J., Bulavin, D. V., \& Ansari, N. H. (2015). Attenuation of p38alpha MAPK stress response signaling delays the in vivo aging of skeletal muscle myofibers and progenitor cells. Aging (Albany NY), 7(9), 718-733. doi:10.18632/aging.100802

Perluigi, M., Di Domenico, F., \& Butterfield, D. A. (2015). mTOR signaling in aging and neurodegeneration: At the crossroad between metabolism dysfunction and impairment of autophagy. Neurobiol Dis. doi:10.1016/j.nbd.2015.03.014

Pertusa, M., Garcia-Matas, S., Rodriguez-Farre, E., Sanfeliu, C., \& Cristofol, R. (2007). Astrocytes aged in vitro show a decreased neuroprotective capacity. $J$ Neurochem, 101(3), 794-805. doi:10.1111/j.1471-4159.2006.04369.x

Pospelova, T. V., Bykova, T. V., Zubova, S. G., Katolikova, N. V., Yartzeva, N. M., \& Pospelov, V. A. (2013). Rapamycin induces pluripotent genes associated with avoidance of replicative senescence. Cell Cycle, 12(24), 3841-3851. doi:10.4161/cc. 27396

Pospelova, T. V., Leontieva, O. V., Bykova, T. V., Zubova, S. G., Pospelov, V. A., \& Blagosklonny, M. V. (2012). Suppression of replicative senescence by rapamycin in rodent embryonic cells. Cell Cycle, 11(12), 2402-2407. doi:10.4161/cc.20882

Rajawat, Y. S., Hilioti, Z., \& Bossis, I. (2009). Aging: central role for autophagy and the lysosomal degradative system. Ageing Res Rev, 8(3), 199-213. doi:10.1016/j.arr.2009.05.001

Rodier, F., \& Campisi, J. (2011). Four faces of cellular senescence. J Cell Biol, 192(4), 547-556. doi:10.1083/jcb.201009094

Roth, D. M., \& Balch, W. E. (2011). Modeling general proteostasis: proteome balance in health and disease. Curr Opin Cell Biol, 23(2), 126-134. doi:10.1016/j.ceb.2010.11.001

Salminen, A., Ojala, J., Kaarniranta, K., Haapasalo, A., Hiltunen, M., \& Soininen, H. (2011). Astrocytes in the aging brain express characteristics of senescenceassociated secretory phenotype. Eur $J$ Neurosci, 34(1), 3-11. doi:10.1111/j.1460-9568.2011.07738.x 
Scialo, F., Sriram, A., Naudi, A., Ayala, V., Jove, M., Pamplona, R., \& Sanz, A. (2015). Target of rapamycin activation predicts lifespan in fruit flies. Cell Cycle, 14(18), 2949-2958. doi:10.1080/15384101.2015.1071745

Schneider, J. L., \& Cuervo, A. M. (2014). Autophagy and human disease: emerging themes. Curr Opin Genet Dev, 26, 16-23. doi:10.1016/j.gde.2014.04.003

Shao, S., Li, S., Qin, Y., Wang, X., Yang, Y., Bai, H., . . Wang, C. (2014). Spautin-1, a novel autophagy inhibitor, enhances imatinib-induced apoptosis in chronic myeloid leukemia. Int J Oncol, 44(5), 1661-1668. doi:10.3892/ijo.2014.2313

Shimi, T., Butin-Israeli, V., Adam, S. A., Hamanaka, R. B., Goldman, A. E., Lucas, C. A., ... Goldman, R. D. (2011). The role of nuclear lamin B1 in cell proliferation and senescence. Genes Dev, 25(24), 2579-2593. doi:10.1101/gad.179515.111

Sofroniew, M. V., \& Vinters, H. V. (2010). Astrocytes: biology and pathology. Acta Neuropathol, 119(1), 7-35. doi:10.1007/s00401-009-0619-8

Springer, M. Z., \& Macleod, K. F. (2016). In Brief: Mitophagy: mechanisms and role in human disease. J Pathol, 240(3), 253-255. doi:10.1002/path.4774

Storer, M., Mas, A., Robert-Moreno, A., Pecoraro, M., Ortells, M. C., Di Giacomo, V., . . . Keyes, W. M. (2013). Senescence is a developmental mechanism that contributes to embryonic growth and patterning. Cell, 155(5), 1119-1130. doi:10.1016/j.cell.2013.10.041

Tanida, I. (2011). Autophagy basics. Microbiol Immunol, 55(1), 1-11. doi:10.1111/j.1348-0421.2010.00271.x

Ting, K. K., Brew, B. J., \& Guillemin, G. J. (2009). Effect of quinolinic acid on human astrocytes morphology and functions: implications in Alzheimer's disease. $J$ Neuroinflammation, 6, 36. doi:10.1186/1742-2094-6-36

Torres, C., Lewis, L., \& Cristofalo, V. J. (2006). Proteasome inhibitors shorten replicative life span and induce a senescent-like phenotype of human fibroblasts. J Cell Physiol, 207(3), 845-853. doi:10.1002/jcp.20630

Tramutola, A., Triplett, J. C., Di Domenico, F., Niedowicz, D. M., Murphy, M. P., Coccia, R., . . Butterfield, D. A. (2015). Alteration of mTOR signaling occurs early in the progression of Alzheimer disease (AD): analysis of brain from subjects with pre-clinical $A D$, amnestic mild cognitive impairment and latestage AD. J Neurochem. doi:10.1111/jnc. 13037

Triana-Martinez, F., Lopez-Diazguerrero, N. E., Maciel-Baron, L. A., MoralesRosales, S. L., Galvan-Arzate, S., Fernandez-Perrino, F. J., . . Konigsberg, M. (2014). Cell proliferation arrest and redox state status as part of different stages during senescence establishment in mouse fibroblasts. Biogerontology, 15(2), 165-176. doi:10.1007/s10522-013-9488-6

Triana-Martinez, F., Pedraza-Vazquez, G., Maciel-Baron, L. A., \& Konigsberg, M. (2016). Reflections on the role of senescence during development and aging. Arch Biochem Biophys, 598, 40-49. doi:10.1016/j.abb.2016.04.004

Valdor, R., Mocholi, E., Botbol, Y., Guerrero-Ros, I., Chandra, D., Koga, H., . . . Macian, F. (2014). Chaperone-mediated autophagy regulates $T$ cell responses through targeted degradation of negative regulators of $\mathrm{T}$ cell activation. Nat Immunol, 15(11), 1046-1054. doi:10.1038/ni.3003 
Wang, Q., \& Ren, J. (2016). mTOR-Independent autophagy inducer trehalose rescues against insulin resistance-induced myocardial contractile anomalies: Role of p38 MAPK and Foxo1. Pharmacol Res, 111, 357-373. doi:10.1016/j.phrs.2016.06.024

Webber, J. L., \& Tooze, S. A. (2010). Coordinated regulation of autophagy by p38alpha MAPK through mAtg9 and p38IP. EMBO J, 29(1), 27-40. doi:10.1038/emboj.2009.321

Wei, Y., An, Z., Zou, Z., Sumpter, R., Su, M., Zang, X., . . Levine, B. (2015). The stress-responsive kinases MAPKAPK2/MAPKAPK3 activate starvationinduced autophagy through Beclin 1 phosphorylation. Elife, 4. doi:10.7554/eLife.05289

Wu, D., \& Cederbaum, A. I. (2013). Inhibition of autophagy promotes CYP2E1dependent toxicity in HepG2 cells via elevated oxidative stress, mitochondria dysfunction and activation of p38 and JNK MAPK. Redox Biology, 1, 552-565. doi:10.1016/j.redox.2013.10.008

Xiao, J., Feng, X., Huang, X. Y., Huang, Z., Huang, Y., Li, C., . . Long, X. D. (2016). Spautin-1 Ameliorates Acute Pancreatitis via Inhibiting Impaired Autophagy and Alleviating Calcium Overload. Mol Med, 22. doi:10.2119/molmed.2016.00034

Young, A. R., Narita, M., Ferreira, M., Kirschner, K., Sadaie, M., Darot, J. F., . . . Narita, M. (2009). Autophagy mediates the mitotic senescence transition. Genes Dev, 23(7), 798-803. doi:10.1101/gad.519709

"You are a triumph of natural selection,

every mutation leading to your perfection

and I'll try, and I'll try, and I'll try, to understand..."

Ode to ancestors, Tall Ships, 2012. 